\title{
Penetration of Liquid Fingers into Superheated Fractured Rock
}

\author{
Jens Birkholzer \\ Earth Sciences Division \\ Ernest Orlando Lawrence Berkeley National Laboratory \\ University of California \\ Berkeley, California
}

\begin{abstract}
Water infiltrating down a fracture in unsaturated rock experiences complex fluid-flow and heat-transfer phenomena when entering above-boiling rock temperature regions. Such conditions are expected, for example, after emplacement of heat-generating nuclear waste in underground repositories. A new, efficient semi-analytical method is proposed in this paper that simulates the flow processes of infiltration events subject to vigorous boiling from the adjacent hot rock. It is assumed that liquid flow forms in localized preferential flow paths, and that infiltration events are typically short in duration but large in magnitude relative to the average net infiltration. The new solution scheme is applied to several test cases studying sensitivity to a variety of input parameters. Sample simulations are performed for conditions representative of the potential nuclear waste repository at Yucca Mountain, Nevada. A characteristic parameter is introduced that provides a quick estimate of the relative significance of boiling at a given location of interest.
\end{abstract}

INDEX TERMS: 1829 Hydrology: Groundwater Hydrology; 1875 Hydrology: Unsaturated Zone; 1878: Hydrology: Water/energy Interactions

KEYWORDS: finger flow, unsaturated fractured rock, thermal, vaporization

\section{Introduction}

Heat released from high-level nuclear waste packages in a partially saturated environment can have a major impact on moisture distribution and migration. At Yucca Mountain, Nevada, the potential repository horizon is located in thick, partially saturated tuff formations that contain more than $80 \%$ liquid water in the pore space. As formation temperatures approach and exceed the boiling point at prevailing pressures, pore water vaporizes and a hot dry-out region develops in the vicinity of the emplacement tunnels. Since liquid water infiltrating down towards the repository will be subject to strong vaporization, the superheated rock zone forming above the repository may significantly reduce the possibility of water contacting the waste packages [Ramspott, 1991; Nitao et al., 1992; Wilder, 1993; Buscheck and Nitao, 1993]. The amount of infiltrating water that can reach the emplacement tunnels has significant implications for the integrity of the waste canisters and the subsequent release of contaminants.

The thermally driven flow processes to be expected at Yucca Mountain have been analyzed in a combined program of field, laboratory, and theoretical studies. There is a long record of 
mathematical modeling studies devoted to the prediction of the future thermal-hydrological conditions in the unsaturated environment [Nitao et al., 1992; Pruess and Tsang, 1993, 1994; Pruess et al., 1984, 1985, 1988, 1990a, b; Tsang and Pruess, 1987, 1989]. Typically, these studies have demonstrated that a large, superheated dry rock region will form for several thousand years at Yucca Mountain, and that during this period, infiltrating liquid water is not expected to contact waste packages. These findings have been supported by measured data - and associated numerical modeling work - collected from in situ heater experiments, such as the Single Heater Test and the Drift Scale Test, in which conditions around the heat sources are typically "hot and dry," and a significant amount of seepage into drifts is not observed [Tsang and Birkholzer, 1999; Birkholzer and Tsang, 2000].

However, there is concern that the exclusion of liquid water from the hot rocks may not be absolute [Pruess and Tsang, 1994]. The amount of water that can be generated by vaporizationcondensation processes is potentially very large. Condensate will form a halo of elevated liquid saturation just outside the dry-out region, and thus provide a localized source of continuous or episodic water flow. Although the above modeling studies are capable of predicting the relevant physical processes (such as the significant vaporization-condensation cycles), they typically involve some sort of volume averaging and homogenization of heterogeneous formation properties. As a result, such modeling studies tend to underestimate the probability of preferential localized pathways that may carry liquid water at flow rates much larger than average infiltration. Also, since spatially uniform flow in fractures is assumed, they overestimate vaporization effects, caused by the much larger cross-sectional area between the flowing liquid and the adjacent hot rock [Pruess, 1997].

In recent years, a number of small-scale flow visualization experiments - and related theoretical studies - have been performed to analyze localized preferential flow paths in unsaturated sub-boiling fractures [e.g., Glass, 1993; Nicholl et al., 1994; Persoff and Pruess, 1995; Glass and Nicholl, 1996; Pruess, 1998; Su et al., 1999]. It was stated in these studies that liquid flow typically forms in narrow fingers, induced by local aperture variations and gravitational instability. Intermittent flow in unsaturated fractures was experimentally observed by Nicholl et al. [1993], Persoff and Pruess [1995] and Su et al. [1999], who found that capillary differences in individual fractures can yield short-term episodic flow, even when constant inlet flow conditions are maintained. Kneafsey and Pruess [1998] reported similar findings in laboratory experiments performed for above-boiling conditions, analyzing heat-driven two-phase 
flow in artificial fracture replicas. Typically, these observed flow events were small with respect to the water volume carried and the finger geometry. The detailed quantitative results of Su et al. [1999], for example, revealed water volumes of less than a milliliter per episodic flow event flowing in fingers that are a few millimeters wide. Recognizing the possibility of episodic preferential flow, Ho and Wilson [1998] proposed a conceptual model for unsaturated infiltration at Yucca Mountain that assumes discrete ribbon-type vertical flow paths (weeps) of given spacing and episodicity.

The above considerations suggest that the probability of infiltrating water reaching waste emplacement tunnels at above-boiling conditions must be estimated using a preferential-flow model for episodic flow events. In 1996, Phillips presented a one-dimensional analytical solution for gravity-driven infiltration of a liquid finger into superheated rock, giving penetration distance of the tip of the finger versus time. Though the simple conceptual model proposed by Phillips is very useful for understanding basic phenomena, his analytical solution was derived using a heatbalance assumption that makes the solution applicable only at large time scales, ones that exceed the time periods relevant in this study (see Appendix A). Also, Phillips' solution is for continuous infiltration only; thus, the analytical solution cannot answer the question of how far a short-term finger flow event of given water volume can penetrate into the superheated rock before the water has entirely boiled off.

Extending Phillips' conceptual model, we present an exact semi-analytical method in this paper that solves for penetration distance and mass flow of both short-term (episodic) and continuous fingers in superheated fractures. The objective of this paper is to develop a fast and simple algorithm valid for early and late time periods, and to study mechanisms controlling the infiltration of short-term flow events at above-boiling conditions. The solution method features a time-marching algorithm that tracks the movement of water pulses while mass losses resulting from water vaporization are accounted for using an analytical expression of Carslaw and Jaeger [1959]. To illustrate the relevant processes and to analyze their sensitivity to some key parameters, the new method is applied to a variety of test cases, with the hydrogeological and thermal conditions typical for the repository horizon at Yucca Mountain after a few hundred years of waste emplacement. The characteristics of episodic finger flow assumed in these test cases are representative of those observed in the above cited experimental studies.

Figure 1a schematically depicts the processes studied: it is assumed that episodic infiltration events are induced by local aperture variation or gravitational instability somewhere in the 
condensation zone above the repository. Finger-type fast flow is directed towards the superheated region around the waste emplacement tunnels, hereafter referred to as "drifts." Depending on finger flow characteristics as well as temperature and pressure conditions, some liquid pulses will completely vaporize, whereas others may penetrate significantly into the superheated region and eventually reach the waste canisters. Thus, for given episodic flow events, we are interested in the maximum penetration distance of the liquid finger, the apparent front penetration velocity of the finger tip, the decrease of mass flow resulting from boiling, and the possibility that part of the liquid may escape vaporization and eventually reach the emplacement drifts. In the last case, we are also interested in the amount of water arriving at the drift wall. The new semi-analytical solution enables us to evaluate all the above points of interest.

\section{Conceptual and Mathematical Model}

The processes described at the end of Section 1 are studied using a simple conceptual model as depicted in Figure 1b, showing a typical situation above waste emplacement drifts at Yucca Mountain several hundred years after waste emplacement [Phillips, 1996]. A superheated region of rock has developed around the drift, extending to a distance L above the drift crown. As the ambient rock water has long been boiled off, fractures and rock are dry. The temperature field is assumed to be uniform in the lateral $\mathrm{x}$-direction and a function of location in the vertical $\mathrm{z}$-direction $\left(\mathrm{T}_{\mathrm{RI}}=\mathrm{f}(\mathrm{z})\right)$. Pressure is close to atmospheric, since effective pathways for gas pressure release are provided by a well-connected fracture network [Birkholzer and Tsang, 2000].

Above the superheated rock, a sub-boiling region is established that may hold substantial amounts of water, both from ambient saturation of matrix pore volume and condensation of vapor caused by heating. We assume that fast finger flow events of constant mass flow rate $\mathrm{m}_{\mathrm{P}}$ and given pulse duration $t_{P}$ can form somewhere in this sub-boiling region. (The pulse duration denotes the time period needed for the finger to flow past a given location). Note that these pulses may be either episodic with finite $t_{P}$ or continuous with infinite $t_{P}$. The water moves downward under gravity in a single vertical fracture of uniform aperture $(2 b)$. Within the fracture plane, finger flow with uniform ribbon or "finger" width w is assumed. Lateral spreading of the ribbon is not considered, and flow is strictly one-dimensional. (Typically, the ribbon width is much larger than the fracture aperture). This simplified flow concept neglects that finger flow in natural fractures often occurs in more complex tortuous paths, depending on aperture variation 
and fracture geometry. Possible processes are spreading and splitting of fingers, or blockage of flow at low aperture zones, all of which would make the above flow model conservative with respect to the potential penetration into superheated rock. On the other hand, separate fingers may also coalesce, thereby increasing the mass of water and thus enhancing the potential for finger penetration. Inclusion of these complex flow processes is beyond the scope of this paper. However, we expect the simplified flow model to provide an appropriate first-order representation of downward flow, because on average the above conservative and nonconservative processes should somewhat cancel out.

In the sub-boiling region, the liquid finger infiltrating down toward the superheated region is assumed to be in thermal equilibrium with the surrounding rock. By heat conduction from the rock, the water is heated up to almost boiling temperature when the boiling-point isotherm is approached. Because the rock matrix has very low permeability, the only relevant contribution to heat transport in the matrix comes from conduction. Imbibition of the infiltrating water into the rock is neglected. In the sub-boiling region, the mass flow rate $m_{P}$ of the flow event is uniform in space and has a constant duration $t_{P}$.

At time $\mathrm{t}=0$, the liquid finger penetrates past the boiling-point isotherm and enters the superheated region. We assume that the water has already reached boiling temperature $\mathrm{T}_{\mathrm{P}}$ at time $t=0$ and remains at $T_{P}$ for all times $t>0$. As the liquid finger is traveling down the fracture in the superheated region, part of the water vaporizes as a result of the thermal energy provided by the surrounding hot rock faces. We assume that the energy resistance at the contact between the fracture and the rock is negligible. Therefore, the rock surface instantaneously cools to boiling temperature, and a steep temperature gradient is established in the surrounding matrix as soon as the liquid front in the fractures reaches the considered position. Over time, the thermal perturbation penetrates further into the rock, the thermal gradient decreases, and heat flow from the matrix to the fracture reduces. Heat conduction in the matrix is very slow compared to the vertical movement of the liquid pulse. Consequently, the lateral gradient in the rock is much larger than the vertical gradient, and we assume that the conductive heat flow within the matrix and from the matrix to the fracture is strictly lateral, perpendicular to the fracture plane.

The maximum penetration of a given liquid pulse into the superheated region depends on the different time and length scales involved, as well as on the relative intensity of mass flow in the fracture and heat flow in the rock. Considering the above assumptions and neglecting advection 
and diffusion of heat within the liquid ribbon (i.e., constant liquid temperature $T_{P}$ ), we can formulate a simple energy balance equation:

$$
\mathrm{h} \frac{\partial \mathrm{m}(\mathrm{z}, \mathrm{t})}{\partial \mathrm{z}}=-\left.2 \mathrm{wk}_{\mathrm{m}} \frac{\partial \mathrm{T}_{\mathrm{R}}(\mathrm{x}, \mathrm{z}, \mathrm{t})}{\partial \mathrm{x}}\right|_{\mathrm{x}=0} .
$$

The left side of Equation (1) gives the energy required to vaporize a fraction of the liquid mass flow in the fracture, while the right side of Equation (1) denotes the energy supplied from the rock by conduction, calculated from the gradient at the rock-fracture interface. The coordinate $\mathrm{z}$ denotes the distance down the fracture below the undisturbed position of the boiling-point isotherm. The liquid front enters the superheated region at $t=0$. At $z=0$ and $0<t \leq t_{P}$, $\mathrm{m}(\mathrm{z}, \mathrm{t})=\mathrm{m}_{\mathrm{P}}$. Note that the fate of the vapor produced from boiling is not considered when solving Equation (1), because the downward flow of water in the superheated rock is not affected by this vapor transport. While water travels downward with gravity, vapor would migrate upward, eventually reach cooler rock outside of the superheated zone, and condense, thereby contributing to the possible generation of future episodic finger flow. These processes of vapor recirculation and/or pulse generation are beyond the scope of this study.

The lateral temperature distribution in the rock is governed by the one-dimensional heat conduction equation

$$
\frac{\partial T_{R}(x, t)}{\partial t}=\kappa \frac{\partial^{2} T_{R}(x, t)}{\partial x^{2}}
$$

with the boundary conditions:

$$
\begin{array}{cc}
T_{R}(0, t)=T_{R I}, & \text { for } z>1(t) \\
T_{R}(0, t)=T_{P}, & \text { for } z \leq 1(t) \\
T_{R}(\infty, t)=T_{R I}, & \text { for all } t
\end{array}
$$

Here, $1(t)$ is the infiltration distance of the liquid front at time $t$. As long as the front has not arrived at location $z$, the rock temperature $T_{R}$ at the fracture-rock interface (i.e., at $x=0$ ) remains undisturbed and equal to the initial rock temperature $\mathrm{T}_{\mathrm{RI}}$. However, as soon as the liquid pulse moves to the considered location, $\mathrm{T}_{\mathrm{R}}(0, \mathrm{t})$ instantaneously decreases to the liquid pulse temperature $\mathrm{T}_{\mathrm{P}}$. At $\mathrm{x}=\infty$, far away from the fracture, the rock matrix temperature remains unchanged from its initial value $\mathrm{T}_{\mathrm{RI}}$. (This latter boundary condition could be relaxed, however, and temperature boundary condition could be assumed at a finite distance into the rock, e.g., a constant temperature or a given heat flux.) 
For the matrix conduction problem as given above, an analytical solution is readily available [e.g., Carslaw and Jaeger, 1959, pp. 58ff]. Let $\mathrm{t}_{0}(\mathrm{z})$ be the time interval after initial infiltration $\operatorname{across} \mathrm{z}=0$ until the arrival of the tip of the liquid finger at location $\mathrm{z}$. Then, the lateral rock temperature distribution at location $\mathrm{z}$ and time $\mathrm{t}$ is given as

$$
\mathrm{T}_{\mathrm{R}}(\mathrm{x}, \mathrm{z}, \mathrm{t})=\mathrm{T}_{\mathrm{P}}+\left(\mathrm{T}_{\mathrm{RI}}-\mathrm{T}_{\mathrm{P}}\right) \operatorname{erf}\left(\frac{\mathrm{x}}{2 \sqrt{\kappa\left(\mathrm{t}-\mathrm{t}_{0}(\mathrm{z})\right)}}\right), \quad \text { for } \mathrm{z} \leq 1(\mathrm{t}), \mathrm{t}>\mathrm{t}_{0}(\mathrm{z})
$$

while the temperature gradient at $\mathrm{x}=0$ becomes

$$
\left.\frac{\partial \mathrm{T}_{\mathrm{R}}}{\partial \mathrm{x}}(\mathrm{z}, \mathrm{t})\right|_{\mathrm{x}=0}=\frac{\mathrm{T}_{\mathrm{RI}}-\mathrm{T}_{\mathrm{P}}}{\sqrt{\pi \kappa\left(\mathrm{t}-\mathrm{t}_{0}(\mathrm{z})\right)}} .
$$

Inserting Equation (5) into Equation (1) and performing slight rearrangements, we get

$$
\frac{\partial \mathrm{m}(\mathrm{z}, \mathrm{t})}{\partial \mathrm{z}}=-\frac{2 \mathrm{wk}_{\mathrm{m}}}{\mathrm{h}} \frac{\mathrm{T}_{\mathrm{RI}}-\mathrm{T}_{\mathrm{P}}}{\sqrt{\pi \kappa\left(\mathrm{t}-\mathrm{t}_{0}(\mathrm{z})\right)}} .
$$

This equation is valid as long as the thermal perturbation in the rock is nearly uniform across the width of the liquid finger. Since thermal perturbation grows with $(\kappa \mathrm{t})^{1 / 2}$, the maximum time scale associated with uniform thermal perturbation is of order

$$
\mathrm{t}_{\mathrm{m}}=\frac{\mathrm{w}^{2}}{\kappa} \text {. }
$$

For $\mathrm{t}>\mathrm{t}_{\mathrm{m}}$, the nearly one-dimensional heat flow perpendicular to the fracture-rock interface transforms to a more circular spreading of heat, and Equation (6) can no longer be applied. However, in most cases of practical concern, $\mathrm{t}_{\mathrm{m}}$ is much larger than the time scale of interest.

In a later section (Section 4.5), we will introduce the simple asymptotic expression of Phillips [1996] that gives an approximate solution for the long-term behavior of Equation (6). This solution is only dependent on the magnitude of the liquid pulse and the amount of heat supplied from the rock. The nature of flow in the fracture, generally influenced by gravitational, viscous, and capillary forces, is not included. Apparently, at late times, front penetration is completely dominated by mass losses as a result of vaporization. At early and intermediate times, however, front penetration is governed by a combination of the above processes, and the nature of flow in the liquid ribbon needs to be considered together with vaporization effects.

It is not an easy task to develop a simplified, but still appropriate, conceptual model for the flow characteristics in a liquid finger in response to mass losses as a result of vaporization. We may start by describing undisturbed flow in a sub-boiling environment, just above the superheated region so that the water temperature is already close to boiling. Our simplifying 
assumptions are that flow in the fracture is laminar and fully developed and that a parallel-plate representation of the fracture plane can be applied. As hysteretic effects are neglected (i.e., air entry pressure at the end of the pulse is equal to water entry pressure at the tip of the pulse), only gravity forces and viscous forces are relevant. Using boiling-point values for $\rho_{1}$ and $\mu$, the flow velocity $v_{P}$ in the finger can be approximated as follows:

$$
\mathrm{v}_{\mathrm{P}}=\frac{(2 \mathrm{~b})^{2}}{12} \frac{\rho_{1} \mathrm{~g}}{\mu},
$$

while the mass flow rate $m_{P}$ is given as

$$
\mathrm{m}_{\mathrm{P}}=(2 \mathrm{~b}) \mathrm{w} \rho_{1} \mathrm{v}_{\mathrm{P}}
$$

The crucial question is how flow behavior changes as the pulse enters the superheated region and part of the water is boiled off. Obviously, the relevant processes occur on a very small (pore) scale and cannot be modeled by the well-known characteristic relationships between relative permeability, saturation, and capillary pressure derived for macroscopic scales. For discussion, let us assume that flow in the liquid finger remains dominated by gravity and viscous forces. Then, the relative permeability $\mathrm{k}_{\mathrm{r}}(\mathrm{z}, \mathrm{t})$ is similar to the ratio between the mass flow of the liquid pulse in the superheated rock $\mathrm{m}(\mathrm{z}, \mathrm{t})$ and the undisturbed mass flow $\mathrm{m}_{\mathrm{P}}$. Let us also assume that flow in the liquid finger may become partially saturated with saturation $S_{1}(z, t)\left(0 \leq S_{1}(z, t) \leq 1\right)$, and that the width of the ribbon remains unchanged. Then, the flow velocity in the liquid finger at location $\mathrm{z}$ and time $\mathrm{t}$ is

$$
\mathrm{v}(\mathrm{z}, \mathrm{t})=\frac{1}{\mathrm{~S}_{1}(\mathrm{z}, \mathrm{t})} \frac{\mathrm{m}(\mathrm{z}, \mathrm{t})}{(2 \mathrm{~b}) \mathrm{w} \rho_{1}} .
$$

Scaled by the undisturbed flow velocity $\mathrm{v}_{\mathrm{P}}$, we arrive at the following relationship between dimensionless flow velocity $\mathrm{v}(\mathrm{z}, \mathrm{t}) / \mathrm{v}_{\mathrm{P}}$ and dimensionless mass flow $\mathrm{m}(\mathrm{z}, \mathrm{t}) / \mathrm{m}_{\mathrm{P}}$

$$
\frac{\mathrm{v}(\mathrm{z}, \mathrm{t})}{\mathrm{v}_{\mathrm{P}}}=\frac{1}{\mathrm{~S}_{1}(\mathrm{z}, \mathrm{t})} \frac{\mathrm{m}(\mathrm{z}, \mathrm{t})}{\mathrm{m}_{\mathrm{P}}}=\frac{\mathrm{k}_{\mathrm{r}}(\mathrm{z}, \mathrm{t})}{\mathrm{S}_{1}(\mathrm{z}, \mathrm{t})} \text {. }
$$

We have plotted this relationship in Figure 2, considering different possible scenarios. A lower limit for flow velocity in the superheated environment is provided by assuming that flow is always fully developed and the saturation in the liquid finger remains at its initial value (i.e. $\mathrm{S}_{1}(\mathrm{z}, \mathrm{t})=1$ ). (This scenario was used by Nitao and Buscheck [1991], studying liquid infiltration into a fracture under the influence of matrix imbibition.) Flow velocity in the liquid finger changes linearly with mass flow rate, which gives rise to a significant decrease of $v(z, t)$ as vaporization becomes effective. The assumption of $S_{1}(z, t)=1$ forces the penetrating front to slow 
down such that the liquid finger is always saturated despite the mass losses. Solution of this scenario provides a lower estimate for the front penetration of a liquid pulse, as two mechanisms act to delay the front: (1) a complete vaporization of water at the tip of the pulse, and (2) a decrease in water flow velocity in response to mass losses.

An upper limit for flow velocity is defined assuming that the velocity of water penetrating into the superheated rock remains constant at its initial value $v_{\mathrm{P}}$, as long as water is available $(\mathrm{z} \leq 1(\mathrm{t}))$. From Equation (11), this translates into a scenario in which saturation of the liquid finger decreases linearly with the decreasing mass flow rate (i.e., $S_{1}(z, t)=m(z, t) / m_{P}=k_{r}(z, t)$ ). Here, front penetration is delayed compared to the undisturbed flow velocity $v_{P}$ by only one of the above mechanisms: vaporization of water at the tip of the moving front. Solution of this scenario provides an upper estimate for the front penetration of a liquid pulse.

For illustrative purposes, we have also plotted a typical characteristic relationship for relative permeability as a function of saturation, used for macro-scale representation of partially saturated porous media. As an example, we apply Corey's definition [Corey, 1954] where $\mathrm{k}_{\mathrm{r}}(\mathrm{z}, \mathrm{t})$ $=\left(\mathrm{S}_{1}\right)^{4}$, using a residual saturation value of zero for both liquid and gas phases. Inserting this definition into Equation (11) and replacing $\mathrm{k}_{\mathrm{r}}(\mathrm{z}, \mathrm{t})$ with $\mathrm{m}(\mathrm{z}, \mathrm{t}) / \mathrm{m}_{\mathrm{P}}$ gives dimensionless velocity for this case of $v(z, t) / v_{P}=\left(m(z, t) / m_{P}\right)^{0.75}$. In Figure 2, Corey's curve is bounded between the aforementioned scenarios; however, it is closer to the linear formulation in the first scenario compared to the second constant-velocity scenario. Apparently, the first scenario formulates an extreme example of a macro-scale characteristic function, indicating that the underlying assumption may not be applicable on the relevant pore scale.

It is difficult to postulate which one of the above scenarios is more realistic in a natural fracture. The experiments performed by Kneafsey and Pruess [1998] clearly demonstrate the potential of gravity-driven fingers forming above and penetrating into superheated rock; however, the length scale of the experiment was too small to suggest preference of one scenario over the other. Considering the objective of the present paper, we decided to assess the most conservative (worst-case) scenario, where the flow velocity of water remains constant and retardation of the liquid front is a result of vaporization only. This will provide upper limits for the potential of liquid pulses penetrating into the superheated rock at Yucca Mountain and eventually reaching waste emplacement drifts. Future work should be directed towards appropriately designed laboratory experiments that help to improve our understanding of liquid 
finger flow in hot rock and allow validation (or adjustment) of the simplified assumptions of the above conservative conceptual model.

\section{Semi-Analytical Solution Scheme}

A simple Lagrangian solution approach is developed for the mass flow of liquid pulses in a fractured superheated regime, as described by Equation (6). In this approach, a time-marching algorithm tracks the movement of small submasses of water traveling downwards while considering the liquid mass losses caused by vaporization. This straightforward technique allows for a very fast and robust solution and can serve as a tool to investigate and understand the nature of the physical processes involved.

A schematic of the solution procedure is given in Figure 3. The total liquid mass $\mathrm{M}_{\mathrm{P}}$ of the infiltration event, given as $M_{P}=m_{P} t_{P}$, is discretized into $n_{\text {Mass }}$ small submasses $M_{j}$ ("buckets"). Starting at $\mathrm{t}=0$, these submasses are subsequently introduced into the superheated region at $\mathrm{z}=$ 0 until the episodic infiltration event has ended. With the time-step size chosen as $\mathrm{dt}=\mathrm{t}_{\mathrm{p}} / \mathrm{n}_{\text {Mass }}$, exactly one "bucket" is released within each time step. Following the discussion in Section 2, we assume for the flow of each submass: (1) a constant flow velocity $v_{P}$ independent of the change of mass caused by vaporization, and (2) gravity-driven flow neglecting capillarity differences within the liquid ribbon. We divide the superheated region into uniform vertical space increments of length $\mathrm{dz}=\mathrm{v}_{\mathrm{P}} \mathrm{dt}$. This way we assure that "buckets" move from one space increment $i$ to the next downward space increment $i+1$ within the exact time step interval dt. The total number of space increments $n_{z}$ is given by $n_{z}=L / d z$, where $L$ is the extent of the boiling zone above the location of interest (i.e., the drift crown).

For each submass $\mathrm{M}_{\mathrm{j}}\left(\mathrm{j}=1, \mathrm{n}_{\text {Mass }}\right.$ ), the change of mass caused by water vaporization along the vertical distance $\mathrm{dz}$ is calculated using Equation (6) in its discrete form

$$
\frac{\mathrm{dM}_{\mathrm{j}}}{\mathrm{dz}}=-\mathrm{dt} \frac{2 \mathrm{wk}_{\mathrm{m}}}{\mathrm{h}} \frac{\mathrm{T}_{\mathrm{RI}}-\mathrm{T}_{\mathrm{P}}}{\sqrt{\pi \kappa\left(\mathrm{t}-\mathrm{t}_{0}(\mathrm{z})\right)}} .
$$

Equation (12) can be solved for each submass independently from the other submasses. Solution is trivial as long as the rock temperature field is known at all locations along the flow path of each submass. This is easily achieved by consecutively solving one submass after the other and accounting for the times when the rock temperatures were first being perturbed from the arriving liquid front in the fracture. For each submass $\mathrm{M}_{\mathrm{j}}$, the rock temperature information needed is collected from the solution for the previously released submasses. The mass flow rate $\mathrm{m}(\mathrm{z}, \mathrm{t})$ of 
the liquid pulse is immediately given after solving Equation (12). (The value of submass $\mathrm{M}_{\mathrm{j}} / \mathrm{dt}$ at space increment $\mathrm{i}$ corresponds to $\mathrm{m}(\mathrm{z}, \mathrm{t})$ at $\mathrm{z}=\mathrm{idz}$ and $\mathrm{t}=(\mathrm{j}-1) \mathrm{dt}+\mathrm{idt}$. In this expression for $\mathrm{t}$, the first term, $(j-1) d t$, denotes the time interval from $t=0$ to the time at which submass $M_{j}$ is released; the second term, idt, denotes the time needed for $\mathrm{M}_{\mathrm{j}}$ to flow from $\mathrm{z}=0$ to location $\mathrm{i}$ ).

For a better understanding of the physical processes, let us follow the first few submasses on their way down the superheated regime (Figure 3). For the submass $\mathrm{M}_{1}$, the surrounding rock temperature at any location $\mathrm{z}$ along the fracture is still at initial value $\mathrm{T}_{\mathrm{RI}}$ before $\mathrm{M}_{1}$ arrives. If we solve Equation (12) using the rock temperature distribution at the end of each time step (fully implicit scheme), the time interval in this equation, $\mathrm{t}-\mathrm{t}_{0}(\mathrm{z})$, is simply the time step size $\mathrm{dt}$, for all space increments along the infiltration of submass $\mathrm{M}_{1}$. Consequently, the resulting temperature gradient at the fracture-rock interface is given as

$$
\frac{\mathrm{T}_{\mathrm{RI}}-\mathrm{T}_{\mathrm{P}}}{\sqrt{\pi \kappa \mathrm{dt}}},
$$

which will be referred to as T' hereafter. Because dt is small, T' is very steep, and the available water mass $M_{1}$ vaporizes rapidly. Eventually, at some distance $1_{1}$, the water has completely vanished and the penetration of the first "bucket" has ended.

The second submass $\mathrm{M}_{2}$, introduced immediately after the first one, will move part of the way down in a rock temperature field that has already cooled to boiling temperature $\mathrm{T}_{\mathrm{P}}$ one time step earlier. Thus, along distance $\mathrm{l}_{1}$, the time interval in Equation (12), $\mathrm{t}-\mathrm{t}_{0}(\mathrm{z})$, becomes $2 \mathrm{dt}$ and the temperature gradient at the fracture-rock interface is

$$
\frac{1}{\sqrt{2}}\left(\frac{\mathrm{T}_{\mathrm{RI}}-\mathrm{T}_{\mathrm{P}}}{\sqrt{\pi \kappa \mathrm{dt}}}\right)
$$

The rate of vaporization for submass $\mathrm{M}_{2}$ is smaller than for $\mathrm{M}_{1}$, and it will penetrate further into the superheated region before the available water mass has vanished. Let $l_{2}$ be the maximum penetration of the second "bucket" before the water has completely vaporized. Along the additional penetration distance, $1_{2}-1_{1}$, the temperature of the surrounding rock has not been disturbed earlier, so that the temperature gradient at the fracture-rock interface is equal to T' and the rate of vaporization is as high as for the first "bucket".

It follows that a third "bucket" would see smaller thermal gradients along $1_{2}$ compared to submass $\mathrm{M}_{2}$, and thus penetrate to a distance $\mathrm{l}_{3}>\mathrm{l}_{2}$; a fourth "bucket" would see smaller thermal gradients along $l_{3}$ compared to submass $\mathrm{M}_{3}$ and travel to a distance $1_{4}>1_{3}$, and so forth. On its way down, "bucket" $M_{3}$ would experience rock interface thermal gradients of $T^{\prime} / \sqrt{3}, T^{\prime} / \sqrt{2}$ and 
T' for penetration distances 0 to $l_{1}, 1_{1}>1_{2}$ and $l_{2}>1_{3}$, respectively; while "bucket" $\mathrm{M}_{4}$ faces thermal gradients of $T^{\prime} / \sqrt{4}, T^{\prime} / \sqrt{3}, T^{\prime} / \sqrt{2}$ and $T^{\prime}$ for travel distances 0 to $l_{1}, l_{1}>l_{2}, l_{2}>l_{3}$ and $1_{3}>1_{4}$, respectively. We may generalize these findings for submass $M_{j}\left(j=1, n_{\text {Mass }}\right)$ with an associated maximum penetration distance of $\mathrm{l}_{\mathrm{j}}$. It can easily be found that in a given distance interval, $l_{k-1}-l_{k}(k=1, j)$, the rock surface temperature gradient is as follows:

$$
\frac{1}{\sqrt{\mathrm{j}-(\mathrm{k}-1)}}\left(\frac{\mathrm{T}_{\mathrm{RI}}-\mathrm{T}_{\mathrm{P}}}{\sqrt{\pi \kappa \mathrm{dt}}}\right)=\frac{1}{\sqrt{\mathrm{j}-(\mathrm{k}-1)}} \mathrm{T}_{1} \text {. }
$$

This means that the temperature gradient is always largest at the tip of the front (i.e., for $k=j$ ), and it is smallest at the end of the liquid pulse close to $z=0$ (i.e., for $j=n_{\text {Mass }}$ and $k=1$ ). From one submass $\mathrm{M}_{\mathrm{j}}$ to the next submass $\mathrm{M}_{\mathrm{j}+1}$, the gradient changes by a factor of

$$
\sqrt{\frac{j-(k-1)}{j+1-(k-1)}} .
$$

Several interesting implications follow from the aforementioned simple considerations related to the time-marching solution scheme:

1. The infiltration length of the tip of the moving liquid front versus time can easily be derived by obtaining the maximum penetration distance $l_{j}$ of each submass $M_{j}$ and calculating the time when this submass has reached its maximum penetration.

2. The maximum penetration of an episodic pulse is defined by the distance that the last submass penetrates into the superheated region before it has completely boiled off. At this time, all water has vanished and the liquid pulse flow event has ended.

3. Since submasses of water have completely vaporized at a certain distance from the boiling-point isotherm and only later submasses will reach further infiltration distances, the apparent penetration velocity $\partial 1(\mathrm{t}) / \partial \mathrm{t}$ of the tip of the liquid front is smaller than the actual flow velocity $v_{p}$. The apparent penetration velocity is equal to the actual flow velocity only for the first "bucket". The second is already delayed by one time step dt when it reaches its maximum penetration distance, the third by two time steps, and so forth. The longer the infiltration event, the more the apparent penetration velocity deviates from the actual velocity of flow in the liquid ribbon. Thus, there are two major flow periods: (1) at early times, front propagation is governed by the gravity-driven flow behavior in the fracture, with small influence by heat conduction from the matrix; (2) at later times, boiling of water significantly retards the frontal advance, and the front penetration velocity is much smaller than the gravity-driven flow velocity $v_{P}$. 
4. The factor given in Equation (16) is always smaller than 1, indicating that even for large times there will always be a (small) rock temperature gradient change from one submass to the next one released, and each "bucket" will travel (slightly) further than the previous one. Hence, a continuous infiltration event will never reach a steady-state situation in which the penetration of the liquid front comes to an end. (The assumption of an infinite rock matrix implies that the lateral perturbation of the rock temperature field continues to spread laterally for all times).

5. Even if a liquid pulse reaches the location of interest in the superheated zone (e.g., a waste emplacement drift), the remaining liquid mass may be much smaller than the total mass injected at the top. The cumulative amount of water can easily be derived by adding up the individual submasses arriving at this location.

\section{Application and Results}

To illustrate the processes described above, the new semi-analytical solution scheme is applied to several test cases. These cases have hydrogeological conditions and properties similar to the expected situation at Yucca Mountain after several hundred years of heating. Depending on the final design, the waste packages, placed into underground tunnels, will generate sufficient heat to boil ambient matrix water and establish a dry superheated region of significant extent. In our study, we assume an above-boiling region extending $3 \mathrm{~m}$ above the crown of an emplacement drift. (This value represents the low range of predicted conditions at Yucca Mountain; it was mainly chosen for illustrative purposes). Pressure in the formation is close to atmospheric conditions, and boiling temperature is $T_{P}=96^{\circ} \mathrm{C}$. Temperature at the drift crown is $111^{\circ} \mathrm{C}$. These values relates to a vertical temperature gradient of $\beta=5^{\circ} \mathrm{C} / \mathrm{m}$ when assuming a linear variation in temperature within the superheated region $\left(T_{R I}=T_{P}+\beta z\right)$. Thermal properties of the rock are based on site-specific measurements for the stratigraphic unit in which the major part of the potential geological repository will reside (i.e., the Topopah Spring Lower Lithophysal Unit; see Table 1).

Realistic values of flow rate, duration, and geometry of episodic flow events are difficult to guess, because of significant temporal and spatial variation of flow at Yucca Mountain. It is widely believed that water flow from the condensation zone downward towards the superheated region around drifts may occur episodically in fast pathways, with flow rates much higher than the average infiltration. For demonstration purposes, we shall study two cases that may represent 
a reasonable range of possible episodic flow events. In both cases, a finger width of $\mathrm{w}=0.02 \mathrm{~m}$ shall be assumed. Comparable values of finger width have been measured in laboratory experiments of Nicholl et al. [1994], Kneafsey and Pruess [1998] or Su et al. [1999]. Typical fracture apertures for the densely fractured tuff formations, characterized in the underground testing facility at Yucca Mountain [e.g., CRWMS, 1997], are (2b) $=0.917 \times 10^{-4} \mathrm{~m}($ Case 1) and $(2 \mathrm{~b})=2.490 \times 10^{-4} \mathrm{~m}$ (Case 2). Associated fracture permeabilities are $7.01 \times 10^{-10} \mathrm{~m}^{2}$ and $5.17 \times 10^{-9} \mathrm{~m}^{2}$, respectively. Assuming fully developed, gravity-driven ribbon flow according to Equations (8) and (9), the above fracture properties relate to mass flow rate of $4.0 \times 10^{-5} \mathrm{~kg} / \mathrm{s}$ (Case 1) and $8.0 \times 10^{-4} \mathrm{~kg} / \mathrm{s}$ (Case 2). The respective vertical flow velocity $\mathrm{v}_{P}$ is $2.27 \mathrm{~cm} / \mathrm{s}$ in Case 1 and $16.72 \mathrm{~cm} / \mathrm{s}$ in Case 2.

We may assume at this point that the small, relatively slow flow event in Case 1 is associated with a comparably long duration, $t_{\mathrm{P}}=60 \mathrm{~s}$, while the larger, faster flow event in Case 2 is related to a shorter duration, $t_{P}=3 \mathrm{~s}$. In both cases, the respective total liquid volume $\mathrm{V}_{\mathrm{P}}$ is the same, i.e., $2.4 \mathrm{~mL}$, calculated from $\mathrm{V}_{\mathrm{P}}=\rho_{\mathrm{L}} \mathrm{m}_{\mathrm{P}} \mathrm{t}_{\mathrm{P}}$. We may relate this intermittently flowing water volume to the time- and space-averaged infiltration in the arid zone of Yucca Mountain, which is about 5 to $10 \mathrm{~mm} /$ year at ambient state. For illustration, let us assume one vertical preferential flow path per square meter cross-sectional area. Now, suppose downward infiltration is episodic, and fast flow fingers of $2.4 \mathrm{~mL}$ would occasionally migrate past given locations for short flow periods of $60 \mathrm{~s}$ in Case 1 and $3 \mathrm{~s}$ in Case 2, respectively. Then, from simple mass balance considerations, these short flow periods must be followed by much longer time periods without downward flow to arrive at the average infiltration at Yucca Mountain. Using the upper value of $10 \mathrm{~mm} /$ year, for example, these time periods without finger flow would be about 2.1 hours long. In this way, small episodic flow events such as Cases 1 and 2 can occur at numerous locations within Yucca Mountain at a frequency of about one event every 2 hours. Predictive simulation of the thermal-hydrological conditions during the heating phase of the repository indicates that the average downward flow in the condensation zone may be elevated from ambient infiltration by a factor of ten [Haukwa, 1999]. In this case, assuming elevated downward flow of $100 \mathrm{~mm} / \mathrm{yr}$, the frequency of the above episodic flow events would be 10 times higher.

\subsection{Characteristic Vaporization Rate}


Before presenting detailed numerical results, it seems reasonable to define a characteristic parameter that helps to estimate the relative impact of vaporization on liquid-front movement at the time and length scale of interest. Let us define a characteristic time interval $t^{*}$ as the time needed for the liquid finger to flow from $\mathrm{z}=0$ to $\mathrm{z}=\mathrm{L}$ with velocity $\mathrm{v}_{\mathrm{P}}$. Thus, $\mathrm{t}^{*}$ denotes the front arrival time at the drift crown in absence of vaporization. We may calculate the average temperature gradient at the rock surface for this time interval from Equation (5), with the simplifying assumptions that (1) temperature perturbation starts at $\mathrm{t}=0$ at all locations independent of actual front arrival time (i.e., $\mathrm{t}_{0}(\mathrm{z})=0$ ), and (2) the initial rock temperature distribution is represented by an average value $\bar{T}_{\mathrm{RI}}$. Integration from 0 to $\mathrm{t}^{*}$ and dividing by $\mathrm{t}^{*}$ gives the average gradient

$$
\frac{1}{\mathrm{t} *} \int_{0}^{\mathrm{t}^{*}} \frac{\mathrm{T}_{\mathrm{RI}}-\mathrm{T}_{\mathrm{P}}}{\sqrt{\pi \kappa \mathrm{t}}} \mathrm{dt}=2 \frac{\left(\overline{\mathrm{T}}_{\mathrm{RI}}-\mathrm{T}_{\mathrm{P}}\right)}{\sqrt{\pi \kappa \mathrm{t}}},
$$

which is then introduced into Equation (6). Spatial integration from $z=0$ to $z=L$ yields the approximate change in mass flow that would occur due to vaporization as the liquid front travels distance L into the superheated region. We may relate this change of mass flow to the initial mass flow $\mathrm{m}_{\mathrm{P}}$ and refer to the resulting parameter as the characteristic vaporization rate $\mathrm{V}^{*}$ :

$$
\mathrm{V}^{*}=\frac{1}{\mathrm{~m}_{\mathrm{P}}}\left(\mathrm{L} \frac{2 \mathrm{wk}_{\mathrm{m}}}{\mathrm{h}} 2 \frac{\left(\overline{\mathrm{T}}_{\mathrm{RI}}-\mathrm{T}_{\mathrm{P}}\right)}{\sqrt{\pi \mathrm{t}^{*}}}\right) \text {. }
$$

If $\mathrm{V}^{*}$ is small, the intensity of vaporization is small compared to the magnitude of flow in the liquid ribbon. Neither mass flow rate nor apparent penetration velocity of the tip of the liquid pulse is significantly affected for the time and length scale considered. The time scale considered falls into flow period (1) defined earlier, in which front penetration is primarily governed by the gravity-driven flow behavior. However, if $\mathrm{V}^{*}$ is large, vaporization is intense and mass flow is expected to either decrease significantly along distance L or vanish completely before reaching L. Also, the apparent penetration velocity of the tip of the moving front is strongly delayed compared to the actual flow velocity. Here, the time scale relates to flow period (2), in which front propagation is primarily governed by mass losses caused by boiling. A critical value for $\mathrm{V}^{*}$ that allows us to distinguish between the two flow regimes must be derived from experiments. It is expected that this critical value should be somewhere close to unity.

Table 1 gives the characteristic time and characteristic vaporization rate $\mathrm{V}^{*}$ calculated for the flow events in Case 1 and Case 2 at $\mathrm{L}=3 \mathrm{~m}$. (For the linear initial temperature distribution, $\overline{\mathrm{T}}_{\mathrm{RI}}$ can be readily derived from $\beta \mathrm{L} / 2$.) From the calculated values of $\mathrm{V}^{*}$, Case 1 should be 
strongly influenced by the effects of boiling at the length scale of interest $(\mathrm{L}=3 \mathrm{~m})$, while the flow event in Case 2 should be fairly unaffected. For comparison of different length scales, we have also calculated the characteristic vaporization rate for distances $\mathrm{L}=1.5 \mathrm{~m}$ and $\mathrm{L}=4.5 \mathrm{~m}$. It is evident from these values that the impact of boiling significantly increases with the infiltration distance of the liquid pulse.

\subsection{Results for Cases 1 and 2}

In this section, example results from the new semi-analytical scheme are presented. A main factor of interest is how fast the penetration distance, measured at the tip of the moving liquid front, increases with time. Figures 4 shows the penetration distance versus time for Case 1, exhibiting a front arrival curve typical for a flow event with strong impact of heating at the considered scale $\mathrm{L}=3 \mathrm{~m}$ (characteristic vaporization rate $\mathrm{V}^{*}=1.61$ ). Very soon after the liquid first enters the superheated region, front penetration is already delayed compared to the undisturbed flow velocity $v_{P}$. The further the finger infiltrates, the stronger this effect. The front delay is caused by earlier submasses of water vanishing as a result of boiling and only later released submasses progressing to further penetration lengths. This effect is reflected in the position of the square symbols in Figure 4, showing the location where every $20^{\text {th }}$ submass has vanished and stopped. At early times, when temperature gradients at the fracture-rock interface are steep, penetration of a later "bucket" is much larger compared to an earlier one. At later times, when rock temperature gradients have relaxed and temporal changes are small, the additional penetration of later "buckets" becomes smaller, and front penetration seems to slow down rapidly.

After about $2.24 \mathrm{~m}$, the episodic infiltration event comes to a final stop as all water has vaporized. Hence, for flow events similar to Case 1, the superheated region around a waste emplacement drift supplies an effective safety mechanism that prevents water from entering the tunnels. Note that the maximum pulse penetration relates to the maximum penetration of the last submass of water released at the end of the $60 \mathrm{~s}$ pulse duration. The dashed line indicates the front arrival of infiltration events with duration longer than $60 \mathrm{~s}$. In the present case, water reaches the drift crown if the pulse duration is increased by a factor of about four.

Results are different for the infiltration event in Case 2, presented in Figure 5. The effect of vaporization is much smaller than in Case 1, which is indicated by the small characteristic vaporization rate $\mathrm{V}^{*}=0.22$. Note the different time scale in Figure 5 , as flow velocity $\mathrm{V}_{\mathrm{P}}$ is 
about eight times faster than in the previous case. The penetration length of the tip of the finger increases rapidly, and the apparent penetration velocity is similar to the actual flow velocity. The liquid finger reaches the drift crown after about $18 \mathrm{~s}$, at which time water may start seeping into the tunnel. However, because of vaporization, the total amount of water available for seepage is only $50 \%$ of the total infiltrated mass. Although it is less obvious from the slope of the front arrival curve, the hot rock environment still provides an important safety feature that reduces the amount of water seeping into drifts by a significant percentage. We may ignore the presence of the drift at $\mathrm{z}=3.0 \mathrm{~m}$ and follow the liquid finger down the fractured rock. In this case, the episodic infiltration event comes to a final stop after about $4.73 \mathrm{~m}$. At this distance, the effect of heating is more obvious: the front arrival curve deviates noticeably from the constant-velocity curve. At even larger scales, we may eventually expect to see behavior similar to Case 1, in which vaporization has strong implications for the front penetration.

Let us study the flow behavior of episodic infiltration events at superheated conditions in more detail by analyzing mass flow profiles. Figure 6 gives flow rate as a function of vertical location for Case 1, at $\mathrm{t}=60 \mathrm{~s}, 90 \mathrm{~s}, 120 \mathrm{~s}$, and $150 \mathrm{~s}$. The first time interval $\mathrm{t}=60 \mathrm{~s}$ coincides with the end of the pulse injection at the boiling-point isotherm. (For comparison, we have also plotted the mass flow profile of a liquid pulse in absence of vaporization, at $t=150 \mathrm{~s}$ ). Typically, mass flow is highest at the end of the pulse and flow rates decrease rapidly towards the tip of the moving front. The total amount of water decreases significantly with time: at $t=60 \mathrm{~s}, 78 \%$ of the injected mass is still available, while at $\mathrm{t}=150 \mathrm{~s}, 98 \%$ of the injected mass has already vanished. A few seconds later, infiltration comes to an end. The decline of total mass manifests itself in two ways: First, the magnitude of flow decreases and, second, the vertical extension of the finger becomes smaller. Note that the change of vertical extent stems from submasses vanishing at the tip of the pulse. There is no mechanical or numerical dispersion related to this observation.

Figure 7 shows mass flow profiles for Case 2. Here, the curves are less affected from the superheated environment. In contrast to Case 1, in which the liquid front does not move much further after infiltration at the top has ended, Case 2 exhibits typical characteristics of a short, intense infiltration event flowing with large velocity. The liquid finger moves down the fracture with shape almost intact and vertical extent virtually unchanged. However, the magnitude of flow changes slowly, and at $t=18 \mathrm{~s}$, shortly before reaching the drift crown, $44 \%$ of the total injected water has already vaporized. 
It is obvious from Figures 6 and 7 that the total mass flowing past a given location decreases as the liquid pulse moves down the fracture. The further the infiltrating liquid front has penetrated into the superheated region, the less water is available. Therefore, during the heating phases of the repository, the potential of seepage into drifts at Yucca Mountain will be strongly affected by the extent of the superheated region forming above the drifts. This is demonstrated in Figure 8 , where total breakthrough of mass is plotted as a function of vertical infiltration distance. For the example considered in Case 1,74\% of the injected mass arrives at the tunnel if the boiling-point isotherm is only $1 \mathrm{~m}$ away from the crown. About $10 \%$ of the total injected mass is captured for a superheated region of $2 \mathrm{~m}$ extent, and no water seeps into the drift for infiltration distances above $2.24 \mathrm{~m}$. A similar dependence is observed for Case 2, where total breakthrough of mass is $94 \%$ at $1 \mathrm{~m}, 77 \%$ at $2 \mathrm{~m}$, and $50 \%$ at $3 \mathrm{~m}$.

\subsection{Sensitivity Study}

Sensitivity of the liquid-pulse flow in a superheated regime is studied with respect to a variety of input parameters. From the definition of $\mathrm{V}^{*}$ in Equation (18), the relative effect of boiling is related to properties describing magnitude and geometry of the infiltration event (mass flow rate, ribbon width), the thermal properties of the rock (thermal conductivity and thermal diffusivity), the intrinsic thermal properties of water (specific enthalpy of vaporization), the initial rocktemperature field (average temperature), the fracture aperture (defines flow velocity, which is required to derive $t^{*}$ ) and the length scale of interest. In the following paragraphs, results are presented for parameter variation of mass flow rate and ribbon width, thermal conductivity, initial rock-temperature field, and fracture aperture. The initial rock-temperature field is varied in two different ways: first, uniform gradients of different magnitude are considered; second, different temperature distributions such as a uniform temperature field or a square function of temperature are assumed. Another important parameter, the duration of the infiltration event $t_{P}$, is not specifically discussed in this section. The strong impact of pulse duration becomes immediately obvious in Figures 9 through 12, where front arrival curves are presented for continuous infiltration, with the maximum penetration of a $60 \mathrm{~s}$ pulse indicated by a solid circle.

We use infiltration event Case 1 as the base case and vary one parameter at a time, comparing results with the base case. We also studied parameter variation using Case 2; general findings are similar and will not be presented in this section. Table 2 summarizes the different test cases studied and provides the maximum penetration distance (and related time) that the liquid pulse 
travels in each case. It also gives characteristic properties $\mathrm{t}^{*}$ and $\mathrm{V}^{*}$ for two locations of interest $(1.5 \mathrm{~m}$ and $3.0 \mathrm{~m})$ and lists the cumulative mass of water collected at these locations.

\section{Ribbon width, initial rock temperature gradient and mass flow rate}

The width of the liquid finger, $w$, defines the cross-sectional area for heat conduction from the hot rock surface to the flowing liquid. A larger area allows for more heat flow at the fracturerock interface and results in higher vaporization rates. Cases studied are $\mathrm{w}=0.04 \mathrm{~m}$ and $\mathrm{w}=0.2$ $\mathrm{m}$, compared to the base case value of $\mathrm{w}=0.02 \mathrm{~m}$. Note that all other parameters are unchanged from the base case. The front arrival curves in Figure 9 demonstrate the strong impact of increasing ribbon width. The infiltration of the tip of the liquid pulse deviates much earlier from the constant-flow-velocity curve, and the infiltration event ends at significantly shorter penetration distance. The characteristic values $\mathrm{V}^{*}$ given in Table 2 correlate well with this observed behavior. Note that the solid circles, indicating the maximum penetration distance for each case, fall on one straight line, defined by the flow velocity of the very last submass of the infiltration event. As suggested by the definition of $\mathrm{V}^{*}$ in Equation (18), sensitivity to the initial rock temperature gradient is identical to ribbon width; results for two cases are given in Table 2 $\left(\beta=2.5^{\circ} \mathrm{C} / \mathrm{m}\right.$ and $\left.\beta=10^{\circ} \mathrm{C} / \mathrm{m}\right)$. Moreover, sensitivity to flow rate $\mathrm{m}_{\mathrm{P}}$ is inversely related to ribbon width. The values in Table 2 demonstrate that results obtained with a two (ten) times smaller flow rate are identical to results obtained with a two (ten) times larger ribbon width. Note that only flow rates smaller than the flow rate used in the base case (i.e., $\mathrm{m}_{\mathrm{P}}=4.0 \times 10^{-4}$ $\mathrm{kg} / \mathrm{s}$ ) have been considered in the sensitivity analysis. Flow rates larger than $\mathrm{m}_{\mathrm{P}}=4.0 \times 10^{-4} \mathrm{~kg} / \mathrm{s}$ are not possible without changing the finger geometry, since this value denotes the maximum gravity-driven flow rate in a fully saturated liquid finger of aperture $(2 \mathrm{~b})=0.917 \times 10^{-4} \mathrm{~m}$ and ribbon width $\mathrm{w}=0.02 \mathrm{~m}$. Similarly, smaller ribbon widths than the one used in the base case are not possible without changing other parameters. Therefore, only larger ribbon widths have been considered in the sensitivity study.

\section{Thermal conductivity of the rock matrix}

Results for a change in thermal conductivity are presented in Table 2 and Figure 10. Two cases are analyzed, a small thermal conductivity of $0.6 \mathrm{~W} / \mathrm{m}-\mathrm{K}$ and a large thermal conductivity of $2.4 \mathrm{~W} / \mathrm{m}-\mathrm{K}$. The curves demonstrate that an increase in thermal conductivity gives rise to increased vaporization, which also correlates to the value of $\mathrm{V}^{*}$ given in Table 2. Sensitivity to thermal conductivity is smaller than sensitivity to ribbon width, initial rock-temperature gradient, 
or mass flow rate. Changes in thermal conductivity have two counteracting effects: on the one hand, energy transfer at the fracture-rock interface is linearly related to $\mathrm{k}_{\mathrm{M}}$; on the other hand, the temperature gradient at the fracture-rock interface is inversely related to the square root of $\mathrm{k}_{\mathrm{M}}$.

\section{Initial rock temperature distribution}

The semi-analytical solution scheme allows for any given vertical distribution of the initial rock temperature field above the drift crown. In this paragraph, we study the effect of changing from the assumed uniform vertical gradient to (a) a uniform value and (b) a square function of distance. The latter is defined by

$$
\mathrm{T}_{\mathrm{RI}}(\mathrm{z})=\mathrm{T}_{\mathrm{P}}+\alpha \mathrm{z}^{2}
$$

For the sensitivity analysis, we make sure that the average temperature of the three temperature fields is identical on the length scale of interest. Using $\mathrm{L}=3 \mathrm{~m}$, a boiling temperature of $96^{\circ} \mathrm{C}$, and a base case gradient of $5^{\circ} \mathrm{C} / \mathrm{m}$, the average temperature is $103.5^{\circ} \mathrm{C}$. Thus, the uniform temperature field is assigned a rock temperature of $103.5^{\circ} \mathrm{C}$, and the coefficient $\alpha$ to choose for the square function is $2.5^{\circ} \mathrm{C} / \mathrm{m}^{2}$. Since $\overline{\mathrm{T}}_{\mathrm{RI}}$ remains unchanged, the characteristic vaporization rate $\mathrm{V}^{*}$ at $\mathrm{L}=3 \mathrm{~m}$ is identical in all three cases.

Front arrival curves for the different temperature fields are presented in Figure 11. The uniform-temperature curve exhibits strong boiling-effects at early times after infiltration, as the temperature difference between the infiltrating water and the hot rock surface immediately jumps to $7.5^{\circ} \mathrm{C}$. A much slower response is seen in the square-function curve, where the rock temperature increases slowly at initial times but rapidly at large infiltration lengths. However, in none of the cases is the length scale of interest actually reached by the liquid pulse of duration $\mathrm{t}_{\mathrm{P}}=60 \mathrm{~s}$. Thus, calculating $\mathrm{V}^{*}$ at $\mathrm{L}=3.0 \mathrm{~m}$ may be misleading because the average temperature along the actual flow path of the pulse is different from the average temperature used for $\mathrm{V}^{*}$. It seems more appropriate to analyze the characteristic vaporization rate at a shorter distance, e.g., at $\mathrm{L}=1.5 \mathrm{~m}$. Then, values of $\mathrm{V}^{*}$ correspond well with the observed intensity of vaporization and also relate to the cumulative mass of water collected at $1.5 \mathrm{~m}$ (see Table 2).

For longer pulse duration, an interesting observation can be made at a penetration distance of $\mathrm{L}=3 \mathrm{~m}$. As mentioned above, the average temperature along this distance is identical in all temperature cases, while the vertical distribution is different. Despite these differences, the three front arrival curves meet in one point at $\mathrm{L}=3 \mathrm{~m}$ and $\mathrm{t} \approx 330 \mathrm{~s}$, and the amount of water collected at the drift crown is identical for all cases. This suggests that the apparent penetration velocity 
measured (as well as the cumulative mass collected) at a location $\mathrm{L}$ is independent of the vertical distribution of temperature between $\mathrm{z}=0$ and $\mathrm{L}$, as long as the integrated temperature along this distance is identical. For time periods larger than $\mathrm{t} \approx 330 \mathrm{~s}$, the early-time front arrival pattern of the three curves is reversed. Now the square-function case exhibits the strongest impact of vaporization, as a result of rapidly increasing rock temperatures.

\section{Fracture aperture}

Variation of fracture aperture changes the flow velocity of the liquid pulse (see Equation (8)), and thus influences the time scales for heat conduction in the rock and subsequent vaporization of water. This has two counteracting effects: as the water moves faster along the adjacent rock surfaces, less time is available for conductive transfer of heat, decreasing the effect of boiling. On the other hand, the temperature gradients at the fracture-rock interface remain very steep, giving rise to increased vaporization.

Two cases with larger fracture aperture are studied in this section, $(2 \mathrm{~b})=1.25 \times 10^{-4} \mathrm{~m}$ and $(2 \mathrm{~b})=2.5 \times 10^{-4} \mathrm{~m}$. These values relate to flow velocities of $4.21 \mathrm{~cm} / \mathrm{s}$ and $16.86 \mathrm{~cm} / \mathrm{s}$, compared to $2.27 \mathrm{~cm} / \mathrm{s}$ in the base case. Figure 12 shows that variation in fracture aperture significantly changes the early-time behavior, in which the apparent penetration velocity of the tip of the front is nearly equal to the flow velocity of the liquid. However, with increasing infiltration distance, front penetration slows down in all three cases, and the larger the aperture, the more rapid the decrease of apparent penetration velocity. From the slope of the curves, we expect that all three cases will eventually exhibit a similar long-term asymptotic behavior, independent of flow velocity (see Section 4.5).

Note that the maximum penetration of the $60 \mathrm{~s}$ pulse is identical for all three apertures, and so is the cumulative mass collected at $\mathrm{L}=1.5 \mathrm{~m}$ (Table 2). This suggests the conclusions that both (1) the infiltration distance as a function of pulse duration and (2) the cumulative mass flow as a function of location are insensitive to the actual flow velocity $v_{P}$ of the water.

\subsection{Comparison with TOUGH2 Simulation Runs}

To verify the semi-analytical solution scheme, we perform modeling of the pulse-injection problem using a standard finite-volume scheme. Hereby, the fracture of length $\mathrm{L}=3.0 \mathrm{~m}$ is represented with one-dimensional vertical finite volumes of uniform aperture and thickness. One component (water) is considered available in two co-existing phases (liquid, vapor). At initial state, no liquid water exists in the model domain; conditions are vapor-static at temperature $\mathrm{T}_{\mathrm{RI}}$ 
and atmospheric pressure $\mathrm{P}=87,000 \mathrm{~Pa}$. Starting with $\mathrm{t}=0$, water with an enthalpy of $400 \mathrm{KJ} / \mathrm{kg}$, corresponding to a temperature of approximately $96^{\circ} \mathrm{C}$, is injected at the top of the superheated fracture domain.

Simulations are performed using the TOUGH2 code that allows for the coupled transport of water, vapor, air, and heat in porous and fractured media [Pruess et al., 1999]. For representation of the rock matrix, a special feature of TOUGH2 is applied that accounts for conductive heat exchange between fracture faces and adjacent semi-infinite half-spaces beyond the fracture walls. Following a methodology suggested by Vinsome and Westerveld [1980], TOUGH2 approximates the temperature profile in the semi-infinite conductive rock layer by a simple, yet very accurate trial function. Note that the numerical simulator requires a uniform initial temperature field for the semi-infinite half-space. Therefore, the comparison between TOUGH2 results and results obtained with the new solution scheme is conducted for a uniform initial temperature case with $\mathrm{T}_{\mathrm{RI}}=103.5^{\circ} \mathrm{C}$. The properties chosen for fracture and rock matrix are identical to the properties of Cases 1 and 2 .

Two aspects of the numerical simulation technique deserve mentioning. The first is related to the production of steam as water is being vaporized. To avoid pressurization of the model domain, each fracture volume is connected to a large-volume boundary element. The vapor generated is allowed to release into this boundary element so that pressure in the model domain remains at atmospheric conditions. The second aspect considers the functional relationship between capillary pressure, saturation, and relative permeability that needs to be prescribed in TOUGH2. To precisely reproduce the hydraulic conditions assumed in the new semi-analytical solution scheme, we chose to neglect capillary forces while defining a simple linear relative permeability function with $\mathrm{k}_{\mathrm{r}}=\mathrm{S}_{\mathrm{l}}$. This guarantees a constant value of flow velocity $\mathrm{v}_{\mathrm{P}}$ for the infiltrating liquid pulse, independent of the decrease in mass flow rate (saturation) along the infiltration distance.

For both solution methods, two different vertical discretizations with increments of $1 \mathrm{~mm}$ and $4 \mathrm{~mm}$ were analyzed. Note that in the semi-analytical solution, the size of vertical increments $\mathrm{dz}$ is related to time step size $\mathrm{dt}$ from $\mathrm{dz}=\mathrm{v}_{\mathrm{P}} \mathrm{dt}$, while the number of submasses is $\mathrm{n}_{\text {Mass }}=\mathrm{t}_{\mathrm{p}} / \mathrm{dt}$ ( $\mathrm{see}$ Section 3). From these relations, the number of submasses in Case 1 would be 1,361 and 340 for grid sizes of $1 \mathrm{~mm}$ and $4 \mathrm{~mm}$, respectively; in Case 2, the respective number of submasses is 502 and 125 . 
Results for the different solution schemes and discretizations are presented in Figure 13 in the form of dimensionless mass flow profiles $\left(\mathrm{m}(\mathrm{z}, \mathrm{t}) / \mathrm{m}_{\mathrm{P}}\right)$, for Case 1 at $90 \mathrm{~s}$ and for Case 2 at $18 \mathrm{~s}$. Compared to the new semi-analytical scheme, the finite-volume simulations performed are very sensitive to the vertical discretization. While the two mass flow profiles calculated with the semi-analytical scheme are virtually identical, the TOUGH2 results arrive at significantly different front penetration patterns for the two grid sizes, with the $1 \mathrm{~mm}$ discretization giving the better agreement with the semi-analytical solution. Results also indicate that the less refined the TOUGH2 grid, the shorter the simulated maximum infiltration of the liquid finger, and the smaller the cumulative mass flow collected at a given location. Evidently, this effect is related to numerical dispersion phenomena that increase the available cross-sectional area for conductive heat transfer. This finding has two important implications: (1) standard Eulerian solution schemes using fixed grids (FEM, FDM, FVM) require highly refined discretizations for simulating flow events and heat exchange processes that significantly depend on dispersion characteristics; (2) natural (physical) dispersion processes, e.g., stemming from fracture aperture variation, may significantly increase the effect of vaporization on the propagating pulse flow.

Overall, the agreement between TOUGH2 results obtained with fine discretization and the new time-marching scheme is good. The main attributes of episodic pulse flow in a superheated regime are well captured in both Cases 1 and 2, which becomes particularly evident in comparison to the profiles of a front moving in absence of vaporization. However, noticeable differences remain between the two methods, caused by the nature of the Eulerian versus Lagrangian solution schemes. A finite-volume scheme will never be able to approximate the sharp-front propagation capability of a Lagrangian solution method precisely. In terms of predicting the potential seepage into tunnels at Yucca Mountain, the new solution technique gives conservative estimates, since no accounting is made for spreading of the pulse.

\subsection{Comparison with Analytical Solution for Long-term Asymptotic Flow Behavior}

At large time scales, the front penetration of a liquid pulse can be estimated from an analytical solution given by Phillips [1996] (see Appendix A). Figure 14 shows this analytical solution compared with the simulation results of Section 4.2 for a time period of 50,000 s, using the properties given in Case 1 and applying continuous infiltration. (Note that the maximum time scale $t_{m}$ defined by Equation (7) is exceeded for this time period. We get around this by 
increasing the ribbon width until Equation (7) is satisfied. Scaling mass flow rate by the same factor guarantees that the simulation results are identical to Case 1). Also plotted is the constantvelocity curve $1(t)=v_{P} t$, with $v_{P}=2.27 \mathrm{~cm} / \mathrm{s}$ for Case 1 . Clearly, the analytical solution agrees favorably with the new semi-analytical method at large times and defines an asymptotic approximation function to estimate the long-term behavior of pulse infiltration. Similarly, the constant-velocity curve forms an asymptotic solution for very early times. The intermediate time scale, however, which is relevant in most cases of short-term episodic pulse events, cannot be represented by any of the approximate solutions. The exact solution must be used, as calculated from the new semi-analytical solution scheme.

\section{Summary and Conclusions}

A new semi-analytical method is presented for calculating the transient gravity-driven flow of liquid fingers in superheated fractured rock. The method is based on a simplified conceptual model of the complex fluid-flow and heat-transfer behavior in a vertical fracture surrounded by hot rock. The solution scheme features a time-marching algorithm that tracks the propagation of finite submasses of water, while an analytical solution is applied to consider mass losses resulting from heat conduction and subsequent boiling from the adjacent hot rock. Several relevant phenomena of pulse flow can be readily explained from simple considerations related to the mass-tracking conceptual model. Note that the solution scheme can be adopted to comparable problems of liquid finger flow (e.g., when considering effects of matrix imbibition).

The new numerical algorithm is robust and very fast, thus allowing for time-consuming Monte-Carlo type analyses. Simulation results from the new solution compare favorably with results derived from an analytical asymptotic solution as well as with results obtained using a standard finite-volume simulator (i.e., simulator TOUGH2 for non-isothermal flow of multicomponent, multiphase fluids; Pruess et al. [1999]). The simulation time required for the TOUGH2 runs is several orders of magnitude higher, because of the extreme nonlinearities and the vast range of intrinsic time scales involved in the problem.

A number of test cases were studied using the semi-analytical method, with property ranges somewhat typical for the future conditions at the potential nuclear waste repository in Yucca Mountain, Nevada. A sensitivity study was performed to analyze the relative impact of different parameters. Several conclusions can be reached from this work: 
1. Vigorous boiling of the infiltrating water has a strong effect on the front propagation of liquid-finger flow. Vaporization forces the apparent penetration velocity of the tip of the finger to be much slower than the flow velocity of the water. For episodic flow events, the maximum penetration of the liquid front is given by the distance that the last submass infiltrates into the superheated region before it has completely boiled away. Typically, the maximum penetration for the cases considered in our study is in the range of only a few vertical meters.

2. The cumulative mass of water collected at given locations in the superheated region is often much smaller than the initial mass of the liquid finger, because a large fraction of the incoming water vaporizes before reaching the location.

3. Results of the sensitivity study suggest that pulse flow in superheated rock is significantly affected by the magnitude and duration of the flow event, the geometric form of the finger (i.e., ribbon width), and the initial rock temperature field (both average temperature and temperature distribution). Less impact was observed from changes in thermal conductivity of the rock and changes in fracture aperture, as counteracting effects of parameter variation were observed in these cases.

4. A characteristic parameter defined in this paper provides a fast initial estimate for the relative impact of boiling on liquid finger flow. The characteristic vaporization rate $\mathrm{V}^{*}$ compares the approximate mass loss caused by boiling with the initial liquid mass of the flow event, calculated at the time and length scale of interest. For the cases studied, values of $\mathrm{V}^{*}$ corresponded very well with the observed flow behavior.

5. For initial rock temperature distributions that follow simple functions in $\mathrm{z}$, the long-term behavior of pulse penetration can be approximated by asymptotic analytical expressions [Birkholzer, this issue]. At early times, pulse penetration is bounded by the constantvelocity curve, neglecting the effect of boiling. However, for most cases of short-term episodic pulse flow, an intermediate time period is relevant that cannot be represented by the asymptotic solutions.

With respect to the conditions at Yucca Mountain the heat generated from the waste packages is apparently sufficient to reduce the probability of seepage into emplacement tunnels by a significant amount, for the time period that repository temperatures are above boiling. However, the simulations performed in this work are mainly for illustration and demonstration purposes, and a detailed Monte-Carlo-type analysis would be needed to properly represent the 
possible ranges of heterogeneous formation properties at Yucca Mountain. Also note that the conceptual model proposed in this paper uses conservative assumptions that tend to overestimate the maximum penetration of a liquid pulse and the cumulative mass collected at a given location. Such conservative assumptions include, for example, neglecting the effect of matrix imbibition, assuming a constant flow velocity of the liquid, and neglecting the possibility that open tunnel cavities may form a capillary barrier for pulse flow. However, another assumption of the conceptual model may be nonconservative: we apply an instantaneous cooling boundary condition at the rock surface upon arrival of the cooler liquid (negligible energy resistance at the contact point). This may not be correct for very fast pulse flow, where a vapor halo may form between the liquid water and the hot rock wall, reducing the thermal conductivity at the interface. The validity of our assumptions and the potential impact of additional processes shall be studied in a proposed future laboratory experiment. 


\section{Nomenclature}

$\mathrm{C}_{\mathrm{m}} \quad$ rock heat capacity $(\mathrm{J} / \mathrm{kg}-\mathrm{K})$

dt time step (s)

$\mathrm{dz} \quad$ vertical space increment $(\mathrm{m})$

g gravitational acceleration $\left(\mathrm{m} / \mathrm{s}^{2}\right)$

$\mathrm{h}$ specific enthalpy of vaporization $(\mathrm{J} / \mathrm{kg})$

$\mathrm{k}_{\mathrm{m}} \quad$ rock thermal conductivity $(\mathrm{W} / \mathrm{m}-\mathrm{K})$

$\mathrm{k}_{\mathrm{r}} \quad$ relative permeability

$\mathrm{L} \quad$ distance from $\mathrm{z}=0$ to location of interest (m)

$1(\mathrm{t})$ penetration distance of the tip of the liquid front at time $t(\mathrm{~m})$

$\mathrm{M}_{\mathrm{P}} \quad$ total initial mass of infiltration event $(\mathrm{kg})$

$\mathrm{M}_{\mathrm{j}} \quad$ submass $(\mathrm{kg})$

$m_{P} \quad$ initial mass flow rate of infiltration event $(\mathrm{kg} / \mathrm{s})$

$\mathrm{m}$ mass flow rate $(\mathrm{kg} / \mathrm{s})$

$\mathrm{n}_{\text {Mass }}$ number of submasses

$\mathrm{n}_{\mathrm{z}} \quad$ number of space increments

$\mathrm{P} \quad$ pressure $(\mathrm{Pa})$

$\mathrm{S}_{1} \quad$ liquid saturation

$\mathrm{T}_{\mathrm{P}} \quad$ liquid (boiling) temperature $\left({ }^{\circ} \mathrm{C}\right)$

$\mathrm{T}_{\mathrm{R}} \quad$ rock temperature $\left({ }^{\circ} \mathrm{C}\right)$

$\mathrm{T}_{\mathrm{RI}} \quad$ initial rock temperature $\left({ }^{\circ} \mathrm{C}\right)$

T' temperature gradient at fracture-rock interface $\left({ }^{\circ} \mathrm{C} / \mathrm{m}\right)$

t time (s)

t* characteristic time (s)

$t_{P} \quad$ duration of infiltration event (s)

$\mathrm{t}_{0}(\mathrm{z})$ time interval after initial infiltration until arrival of the liquid finger at location $\mathrm{z}(\mathrm{s})$

$t_{\mathrm{m}} \quad$ maximum time interval for validity of 1-D heat conduction assumption (s)

$t_{a} \quad$ time interval used for definition of validity range of asymptotic solutions (s)

$\mathrm{V}^{*} \quad$ characteristic vaporization rate

$V_{P} \quad$ total initial volume of infiltration event $(\mathrm{mL})$

$\mathrm{V}_{\mathrm{P}} \quad$ flow velocity $(\mathrm{m} / \mathrm{s})$

$\mathrm{w} \quad$ finger width $(\mathrm{m})$

$\mathrm{x} \quad$ distance from fracture wall $(\mathrm{m})$

$\mathrm{z} \quad$ vertical distance $(\mathrm{m})$

(2b) fracture aperture $(\mathrm{m})$

$\alpha \quad$ parameter used for definition of initial rock temperature $\left({ }^{\circ} \mathrm{C} / \mathrm{m}^{2}\right)$

$\beta \quad$ initial rock temperature gradient $\left({ }^{\circ} \mathrm{C} / \mathrm{m}\right)$

$\kappa \quad$ rock thermal diffusivity, given as $\mathrm{k}_{\mathrm{m}} / \rho_{\mathrm{m}} \mathrm{C}_{\mathrm{m}}\left(\mathrm{m}^{2} / \mathrm{s}\right)$

$\mu \quad$ dynamic viscosity $(\mathrm{kg} / \mathrm{m}-\mathrm{s})$

$\rho_{\mathrm{m}} \quad$ rock grain density $\left(\mathrm{kg} / \mathrm{m}^{3}\right)$

$\rho_{1} \quad$ liquid density $\left(\mathrm{kg} / \mathrm{m}^{3}\right)$ 


\section{Acknowledgment}

This work was supported by the Director, Office of Civilian Radioactive Waste Management, U.S. Department of Energy, through Memorandum Purchase Order EA9013MC5X between Bechtel SAIC Company, LLC and the Ernest Orlando Lawrence Berkeley National Laboratory (Berkeley Lab). The support is provided to Berkeley Lab through the U.S. Department of Energy Contract No. DE-AC03-76SF00098. Review and comments of Dan Hawkes and Sumit Mukhopadhyay from Berkeley Lab are gratefully appreciated. We also thank two anonymous reviewers for their helpful comments and suggestions for improving the paper.

\section{Appendix A}

Phillips [1996] developed an analytical solution for the infiltration distance of a liquid finger flowing in superheated fractured rock as a function of time. The solution is based on a conceptual and geometrical model similar to the one introduced in Section 2 of this paper. The proposed validity range is identical to the range defined by Equation (7), giving an upper time constraint $\mathrm{t}_{\mathrm{m}}$. A lower limit is not provided by Phillips [1996], implying that the analytical solution is applicable at all times $\mathrm{t} \leq \mathrm{t}_{\mathrm{m}}$. However, in Figure 14 we have plotted the analytical solution in comparison with our new semi-analytical results and found that it severely overestimates infiltration distance at early times. In fact, Phillips' solution involves such a rapid initial increase of infiltration distance that the corresponding flow velocity is much larger than $\mathrm{V}_{\mathrm{P}}$, the gravity-driven flow velocity in the absence of vaporization (Equation (8)). The constantvelocity curve $1(\mathrm{t})=\mathrm{v}_{\mathrm{P}} \mathrm{t}$ in Figure 14 provides an upper bound for the infiltration distance, because the liquid pulse flow cannot be faster than $v_{P}$. The rapid initial increase infiltration distance calculated by Phillips's solution is clearly unphysical. Consequently, his solution cannot be used for early time periods; however, it does provide an asymptotic approximation of the long-term flow behavior.

Let us analyze Phillips' analytical solution in more detail. Using the nomenclature given in this paper, the governing equation solved for in Phillips [1996] is

$$
\frac{\partial \mathrm{m}(\mathrm{z}, \mathrm{t})}{\partial \mathrm{z}}=-\mathrm{f}_{1} \frac{2 \mathrm{wk}_{\mathrm{m}}}{\mathrm{h}} \frac{\beta \mathrm{z}}{\sqrt{\pi \kappa\left(\mathrm{t}-\mathrm{t}_{0}(\mathrm{z})\right)}},
$$

which is similar to Equation (6). Note that the temperature term in Equation (6), $\left(\mathrm{T}_{\mathrm{RI}}-\mathrm{T}_{\mathrm{P}}\right)$, has been replaced by the term $(\beta z)$, as a uniform vertical gradient $\beta$ of the initial rock temperature field is assumed. (Also note that Phillips introduced an additional factor $f_{1}=2^{1 / 2}$ on the righthand side of Equation (A1)). We have not been able to follow Phillips' rationale for using this factor. Thus, for better comparison with our results in Figure 14, we adjusted the analytical 
solution by using a factor of $f_{1}=1$. This shifts the resulting infiltration curve slightly, but does not change its general behavior.) For solution of Equation (A1), Phillips [1996] utilizes a simple energy balance for the vaporization of water entering the superheated region, assuming that the energy needed to completely boil off the mass of infiltrating water is proportional to the energy extracted from the rock at all times $\mathrm{t} \leq \mathrm{t}_{\mathrm{m}}$. The resulting proportionality between infiltration distance and time, $1(t) \approx t^{1 / 4}$, is used to substitute the unknown time $t_{0}(z)$ in Equation (A1). Then, integration from $\mathrm{z}=0$ to $\mathrm{z}=1(\mathrm{t})$ can be readily performed, and the following relationship for the penetration of the tip of the front as a function of time is derived:

$$
1(t)=\left(\frac{4}{f_{1}^{2} \pi}\right)^{1 / 4}\left(\frac{m_{p} h}{k_{m} \beta}\right)^{1 / 2}\left(\frac{\kappa t}{w^{2}}\right)^{1 / 4} .
$$

The reason for the early-time differences between Equation (A2) and the exact solution is obvious: The above-mentioned energy balance is not valid for small t. At early times, only a small fraction of the infiltrating water boils off, while the bulk of the liquid pulse moves with gravity-driven flow velocity. Thus, the proportionality $1(t) \approx \mathrm{t}^{1 / 4}$ does not hold. At late times, however, the propagation of the tip of the front is dominated by retardation effects caused by boiling, independent of the characteristics of flow in the fracture. (This explains the interesting observation that Phillips' solution is independent of fracture aperture (2b), which governs the gravity-driven flow behavior in the fracture). In this case, the energy balance holds, and Equation (A2) is valid.

To define an adjusted validity range for Phillips' solution, we may calculate the time period $\mathrm{t}_{\mathrm{a}}$ at which Equation (A2) and the constant-velocity curve $1(t)=v_{P} t$ intersect (see Figure 14):

$$
\left(\mathrm{t}_{\mathrm{a}}\right)^{3 / 4}=\frac{1}{\mathrm{v}_{\mathrm{P}}}\left(\frac{4}{\pi}\right)^{1 / 4}\left(\frac{\mathrm{m}_{\mathrm{P}} \mathrm{h}}{\mathrm{k}_{\mathrm{m}} \beta}\right)^{1 / 2}\left(\frac{\kappa}{\mathrm{w}^{2}}\right)^{1 / 4} .
$$

For $\mathrm{t}>\mathrm{t}_{\mathrm{a}}$, Equation (A1) provides an accurate asymptotic solution for the infiltration problem. In conjunction with the limiting condition $t \leq t_{m}$ given in Equation (7), the resulting validity range of Phillips' solution is thus $\mathrm{t}_{\mathrm{a}}<<\mathrm{t} \leq \mathrm{w}^{2} / \kappa$. 


\section{References}

Birkholzer, J.T., and Y.W. Tsang, Modeling the thermal-hydrologic processes in a large-scale underground heater test in partially saturated fractured tuff, Water Resour. Res., 36(6), $1431-1447,2000$.

Buscheck, T.A., and J.J. Nitao, The analysis of repository-heat-driven hydrothermal flow at Yucca Mountain, in Proceedings of the 4th Annual High-Level Radioactive Waste Management Conference, Las Vegas, NV, 449-471, 1993.

Carslaw, H.S., and J.C. Jaeger, Conduction of heat in solids, $2^{\text {nd }}$ edn, Oxford University Press, Oxford, 1959.

Corey, A.T., The interrelation between gas and oil relative permeabilities, Producers Monthly, 38-41, 1954.

CRWMS, Civil Radioactive Waste Management System, Ambient characterization of the drift scale test block, Rep. BADD00000-01717-5705-00001 Rev01, TRW Environ. Safety Syst., Las Vegas, NV, 1997.

Glass, R.J., Modeling gravity-driven fingering in rough-walled fractures using modified percolation theory, in Proceedings of the 4th Annual High-Level Radioactive Waste Management Conference, Las Vegas, NV, 1993.

Glass, R.J., and M.J. Nicholl, Physics of gravity fingering of immiscible fluids within porous media: An overview of current understanding and selected complicating factors, Geoderma, 70, 133-163, 1996.

Haukwa, C.B., Y.-S. Wu, G.S. Bodvarsson, Thermal loading studies using the Yucca Mountain unsaturated zone model, J. Contam. Hydrol., 38(1-3), 217-255, 1999.

Ho, C.K., and M.L. Wilson, Calculation of discrete fracture flow paths using dual-continuum models, in Proceedings of the 8th International High-Level Radioactive Waste Management Conference, Las Vegas, NV, 1998.

Kneafsey, T.J., and K. Pruess, Laboratory experiments on heat-driven two-phase flows in natural and artificial fractures, Water Resour. Res., 34(12), 3349-3367, 1998.

Nicholl M. J., R.J. Glass, and S.W. Wheatcraft, Gravity-driven infiltration instability in initially dry nonhorizontal fractures, Water Resour. Res., 30(9), 2533-2546, 1994. 
Nitao, J.J., and T.A. Buscheck, Infiltration of a liquid front in an unsaturated, fractured porous medium, Water Resour. Res., 27(8), 2099-2112, 1991.

Nitao, J.J., T.A. Buscheck, and D.A. Chesnut, The implications of episodic nonequilibrium fracture-matrix flow on site-suitability and total system performance assessment, in Proceedings of the 3rd Annual High-Level Radioactive Waste Management Conference, Las Vegas, NV, 1992.

Phillips, O.M., Infiltration of a liquid finger down a fracture into superheated rock, Water Resour. Res., 32(6), 1665-1670, 1996.

Persoff, P. and K. Pruess, 2-phase flow visualization and relative permeability measurement in natural rough-walled rock fractures, Water Resour. Res., 31(5), 1175-1186, 1995.

Pruess, K., On vaporizing water flow in hot sub-vertical rock fractures, Transport in Porous Media, 28(3), 335-372, 1997.

Pruess, K., On water seepage and fast preferential flow in heterogeneous, unsaturated rock fractures, J. Contam. Hydrol., 30, 333-362, 1998.

Pruess, K., Oldenburg, K., and G. Moridis, TOUGH2 user's guide, Version 2.0, Rep. LBL43134 Lawrence Berkeley Natl. Lab., Berkeley, CA, 1999.

Pruess, K., and Y.W. Tsang, Thermal modeling for a potential high-level nuclear waste repository at Yucca Mountain, Nevada, Rep. LBL-33597 UC-200, Lawrence Berkeley Natl. Lab., Berkeley, CA, 1993.

Pruess, K., and Y.W. Tsang, Modeling of strongly heat-driven flow processes at a potential highlevel nuclear waste repository at Yucca Mountain, Nevada, Rep. LBL-35381 UC-600, Lawrence Berkeley Natl. Lab., Berkeley, CA, 1994.

Pruess, K., Y.W. Tsang, and J.S.Y. Wang, Numerical studies of fluid and heat flow near a highlevel nuclear waste packages emplaced in partially saturated fractured tuff, Rep. LBL-18552, Lawrence Berkeley Natl. Lab., Berkeley, CA, 1984.

Pruess, K., J.S.Y. Wang, and Y.W. Tsang, Modeling of strongly heat-driven flow in partially saturated fractured porous media, Memoires, XVII, 486-497, 1985. 
Pruess, K., J.S.Y. Wang, and Y.W. Tsang, Effective continuum approximation for modeling fluid and heat flow in fractured porous tuff, SAND86-7000, Rep. Sandia Natl. Lab., Albuquerque, NM, 1988.

Pruess, K., J.S.Y. Wang, and Y.W. Tsang, On thermohydrologic conditions near high-level nuclear wastes emplaced in partially saturated fractured tuff, 1, Simulation studies with explicit consideration of fracture effects, Water Resour. Res., 26, 1235-1248, 1990a.

Pruess, K., J.S.Y. Wang, and Y.W. Tsang, On thermohydrologic conditions near high-level nuclear wastes emplaced in partially saturated fractured tuff, 2, Effective continuum approximations, Water Resour. Res., 26, 1249-1261, 1990 b.

Ramspott, L.D., The constructive use of heat in an unsaturated tuff repository, in Proceedings of the 2nd Annual High-Level Radioactive Waste Management Conference, Las Vegas, NV, 1991.

Su, G.W., J.T. Geller, K. Pruess, and F. Wen, Experimental studies of water seepage and intermittent flow in unsaturated, rough-walled fractures, Water Resour. Res., 35(4), 1019-1037, 1999.

Tsang, Y.W., and J.T. Birkholzer, Predictions and observations of the thermal-hydrological conditions in the single heater test, J. Contam. Hydrol., 38(1-3), 385-425, 1999.

Tsang, Y.W., and K. Pruess, A study of thermally induced convection near a high-level nuclear waste repository in partially saturated fractured tuff, Water Resour. Res., 23, 1958-1966, 1987.

Tsang, Y.W., and K. Pruess, Preliminary studies of gas phase flow effects and moisture migration at Yucca Mountain, Nevada, Rep. LBL-28819, Lawrence Berkeley Natl. Lab., Berkeley, CA, 1989.

Vinsome, P.K.W., and J. Westerveld, A simple method for predicting cap and base rock heat losses in thermal reservoir simulations, J. Canad. Pet. Tech., 19(3), 87-90, 1980.

Wilder, D.G., Alternative strategies - a means for saving money and time on the Yucca Mountain project, in Proceedings of the 4th Annual High-Level Radioactive Waste Management Conference, Las Vegas, NV, 1993. 


\section{Table Captions}

Table 1: Parameters chosen for infiltration events Case 1 and Case 2

Table 2: Characteristic parameters and results for parameter variation related to Case 1. Superscript "*” denotes the base case properties. Values for maximum penetration depth and related time as well as cumulative mass refer to a pulse duration of $60 \mathrm{~s}$.

\section{Figure Captions}

Figure 1: a. Schematic illustration of conceptual model of infiltration in unsaturated fractured rock surrounding heat-generating nuclear waste packages in emplacement tunnels (drifts)

b. Conceptual model for liquid finger flow in a vertical fracture with heat conduction from the adjacent matrix rock

Figure 2: Different concepts for change of flow velocity as a function of mass flow rate

Figure 3: Schematic illustration of the time-marching algorithm proposed for the flow of finite submasses $\mathrm{M}_{\mathrm{j}}$ introduced into superheated rock

Figure 4: Penetration distance versus time for infiltration event Case 1 (dashed line: for continuous pulse)

Figure 5: Penetration distance versus time for infiltration event Case 2 (dashed line: for continuous pulse)

Figure 6: Profiles of mass flow for infiltration event Case 1, at t $=60 \mathrm{~s}, 90 \mathrm{~s}, 120 \mathrm{~s}$, and $150 \mathrm{~s}$

Figure 7: Profiles of mass flow for infiltration event Case 2, at $t=3 \mathrm{~s}, 9 \mathrm{~s}$, and $18 \mathrm{~s}$

Figure 8: Cumulative mass collected at location z, compared to total injected mass (in \%)

Figure 9: Penetration distance versus time for different ribbon widths. Solid circles indicate location and time where infiltration event $t_{P}=60 \mathrm{~s}$ comes to a final stop. Note that results for $\mathrm{w}=0.04 \mathrm{~m}$ are identical to results for $\mathrm{m}_{\mathrm{P}}=2.0 \times 10^{-5} \mathrm{~kg} / \mathrm{s}$ or $\beta=10^{\circ} \mathrm{C} / \mathrm{m}$. Results for $\mathrm{w}=0.2 \mathrm{~m}$ are identical to results for $\mathrm{m}_{\mathrm{P}}=4.0 \times 10^{-6} \mathrm{~kg} / \mathrm{s}$.

Figure 10: Penetration distance versus time for different thermal conductivities. Solid circles indicate location and time where infiltration event $t_{\mathrm{P}}=60 \mathrm{~s}$ comes to a final stop. 
Figure 11: Penetration distance versus time for different initial rock temperature distributions. Solid circles indicate location and time where infiltration event $t_{P}=60 \mathrm{~s}$ comes to a final stop.

Figure 12: Penetration distance versus time for different fracture apertures. Solid circles indicate location and time where infiltration event $t_{P}=60 \mathrm{~s}$ comes to a final stop.

Figure 13: Profiles of dimensionless mass flow for infiltration event Case 1 at $\mathrm{t}=90 \mathrm{~s}$ and infiltration event Case 2 at $18 \mathrm{~s}$. The initial rock temperature is uniform. Results compare new solution scheme with TOUGH2 simulation, using two different vertical discretization lengths of $1 \mathrm{~mm}$ and $4 \mathrm{~mm}$. In Case 1, maximum pulse penetration for the new solution scheme is $1.68 \mathrm{~m}$ with $\mathrm{dz}=1 \mathrm{~mm}$ and $1.64 \mathrm{~m}$ with $\mathrm{dz}=4 \mathrm{~mm}$, while TOUGH2 results give $1.42 \mathrm{~m}$ with $\mathrm{dz}=1 \mathrm{~mm}$ and $1.36 \mathrm{~m}$ with $\mathrm{dz}=4 \mathrm{~mm}$. In Case 2, the cumulative amount of water collected at $\mathrm{L}=3 \mathrm{~m}$ is $50 \%$ of total injected water for both discretizations using the new solution scheme, compared to $39 \%$ for TOUGH2 run with $\mathrm{dz}=1 \mathrm{~mm}$ and $30 \%$ for TOUGH2 run with $4 \mathrm{~mm}$.

Figure 14: Penetration distance versus time, for continuous infiltration. Results compare new solution scheme with analytical solution for asymptotic long-term behavior. 


\section{Tables}

Table 1: Parameters chosen and results obtained for infiltration events Case 1 and Case 2

\begin{tabular}{|c|c|c|}
\hline Parameter & Case 1 & Case 2 \\
\hline Initial mass flow rate $m_{P}$ & $4.0 \times 10^{-5} \mathrm{~kg} / \mathrm{s}$ & $8.0 \times 10^{-3} \mathrm{~kg} / \mathrm{s}$ \\
\hline Duration of infiltration event $t_{P}$ & $60 \mathrm{~s}$ & $3 \mathrm{~s}$ \\
\hline Fracture aperture $(2 b)$ & $0.917 \times 10^{-4} \mathrm{~m}$ & $2.490 \times 10^{-4} \mathrm{~m}$ \\
\hline Finger width w & \multicolumn{2}{|c|}{$0.02 \mathrm{~m}$} \\
\hline Initial rock temperature gradient $\beta$ & \multicolumn{2}{|c|}{$5^{\circ} \mathrm{C} / \mathrm{m}$} \\
\hline Rock thermal conductivity $\mathrm{k}_{\mathrm{m}}$ & \multicolumn{2}{|c|}{$1.2 \mathrm{~W} / \mathrm{m}-\mathrm{K}$} \\
\hline Rock thermal diffusivity $\kappa\left(=\mathrm{k}_{\mathrm{m}} / \rho_{\mathrm{m}} \mathrm{C}_{\mathrm{m}}\right)$ & \multicolumn{2}{|c|}{$5.25 \times 10^{-7} \mathrm{~m}^{2} / \mathrm{s}$} \\
\hline Rock heat capacity $\mathrm{C}_{\mathrm{m}}$ & \multicolumn{2}{|c|}{$900 \mathrm{~J} / \mathrm{kg}-\mathrm{K}$} \\
\hline Rock grain density $\rho_{\mathrm{m}}$ & \multicolumn{2}{|c|}{$2540 \mathrm{~kg} / \mathrm{m}^{3}$} \\
\hline Specific enthalpy of vaporization $h$ & \multicolumn{2}{|c|}{$2.27 \times 10^{6} \mathrm{~J} / \mathrm{kg}$} \\
\hline Liquid (boiling) temperature $T_{P}$ & \multicolumn{2}{|c|}{$96^{\circ} \mathrm{C}$} \\
\hline Dynamic viscosity of water $\mu$ (at boiling) & \multicolumn{2}{|c|}{$2.912 \times 10^{-4} \mathrm{~kg} / \mathrm{m}-\mathrm{s}$} \\
\hline Density of water $\rho_{1}$ (at boiling) & \multicolumn{2}{|c|}{$961 \mathrm{~kg} / \mathrm{m}^{3}$} \\
\hline Gravitational acceleration $\mathrm{g}$ & \multicolumn{2}{|c|}{$9.81 \mathrm{~m} / \mathrm{s}^{2}$} \\
\hline Maximum time interval $t_{m}$ & \multicolumn{2}{|c|}{$762.0 \mathrm{~s}$} \\
\hline Gravity-driven flow velocity $v_{P}$ & $2.27 \mathrm{~cm} / \mathrm{s}$ & $16.72 \mathrm{~cm} / \mathrm{s}$ \\
\hline $\begin{array}{l}\text { Characteristic parameters at } \mathrm{L}=1.5 \mathrm{~m} \text { : } \\
\text { - characteristic time } \mathrm{t}^{*} \\
\text { - characteristic vaporization rate } \mathrm{V}^{*}\end{array}$ & $\begin{array}{c}66.1 \mathrm{~s} \\
0.57\end{array}$ & $\begin{array}{l}9.0 \mathrm{~s} \\
0.08\end{array}$ \\
\hline $\begin{array}{l}\text { Characteristic parameters at } \mathrm{L}=3.0 \mathrm{~m} \text { : } \\
\text { - characteristic time } \mathrm{t}^{*} \\
\text { - characteristic vaporization rate } \mathrm{V}^{*}\end{array}$ & $\begin{array}{c}132.21 \mathrm{~s} \\
1.61\end{array}$ & $\begin{array}{c}17.9 \mathrm{~s} \\
0.22\end{array}$ \\
\hline $\begin{array}{l}\text { Characteristic parameters at } \mathrm{L}=4.5 \mathrm{~m} \text { : } \\
\text { - characteristic time } \mathrm{t}^{*} \\
\text { - characteristic vaporization rate } \mathrm{V}^{*}\end{array}$ & $\begin{array}{c}198.3 \mathrm{~s} \\
2.96\end{array}$ & $\begin{array}{c}26.9 \mathrm{~s} \\
0.40\end{array}$ \\
\hline Maximum penetration & $2.24 \mathrm{~m}$ & $4.73 \mathrm{~m}$ \\
\hline Total mass collected at $\mathrm{z}=1.5 \mathrm{~m}$ & $44.0 \%$ & $87.2 \%$ \\
\hline Total mass collected at $\mathrm{z}=3.0 \mathrm{~m}$ & $0 \%$ & $50.0 \%$ \\
\hline Total mass collected at $\mathrm{z}=4.5 \mathrm{~m}$ & $0 \%$ & $3.2 \%$ \\
\hline
\end{tabular}







Figures

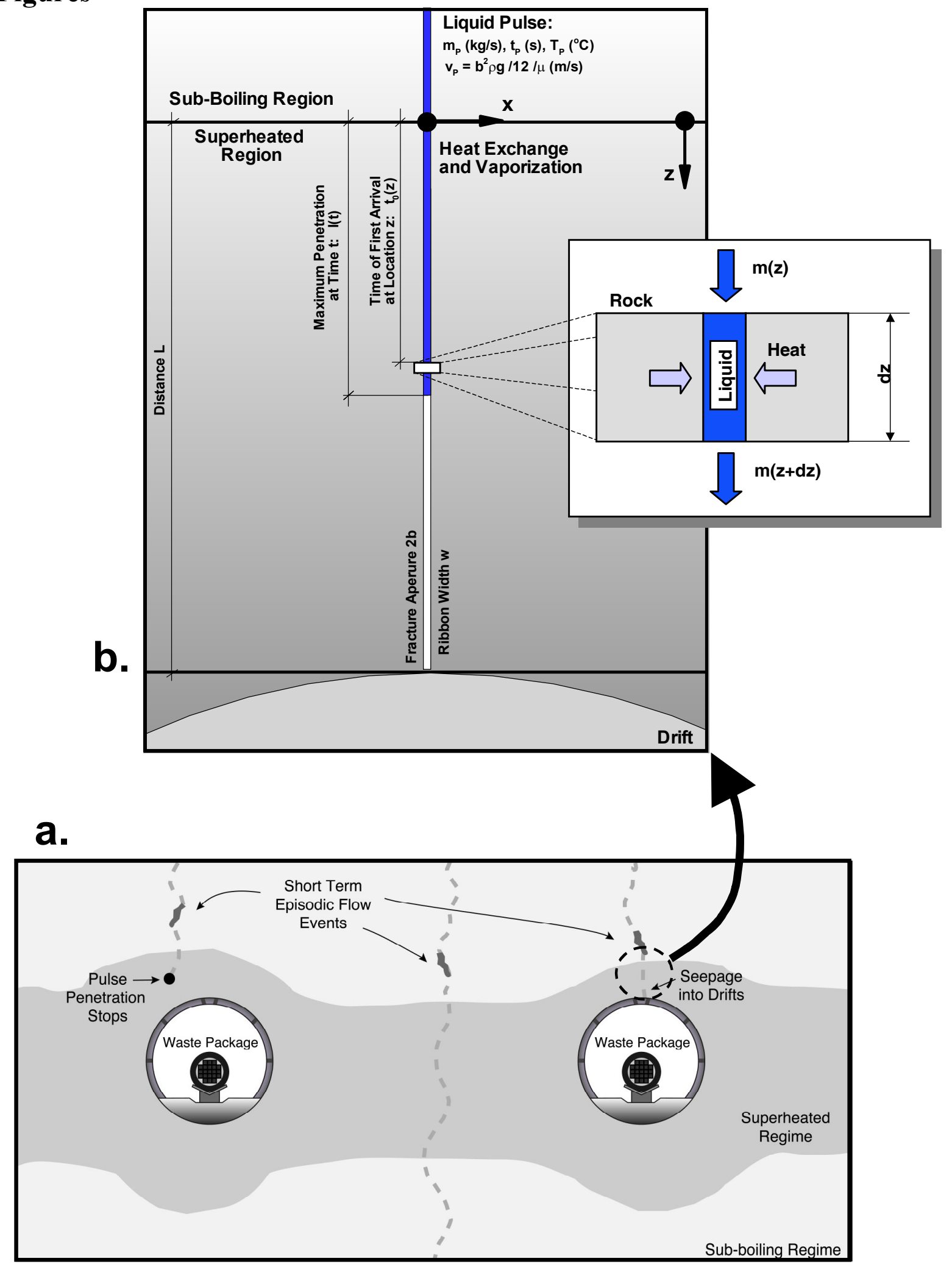

Figure 1: a. Schematic illustration of conceptual model of infiltration in unsaturated fractured rock surrounding heat-generating nuclear waste packages in emplacement tunnels (drifts) b. Conceptual model for liquid finger flow in a vertical fracture with heat conduction from the adjacent matrix rock 


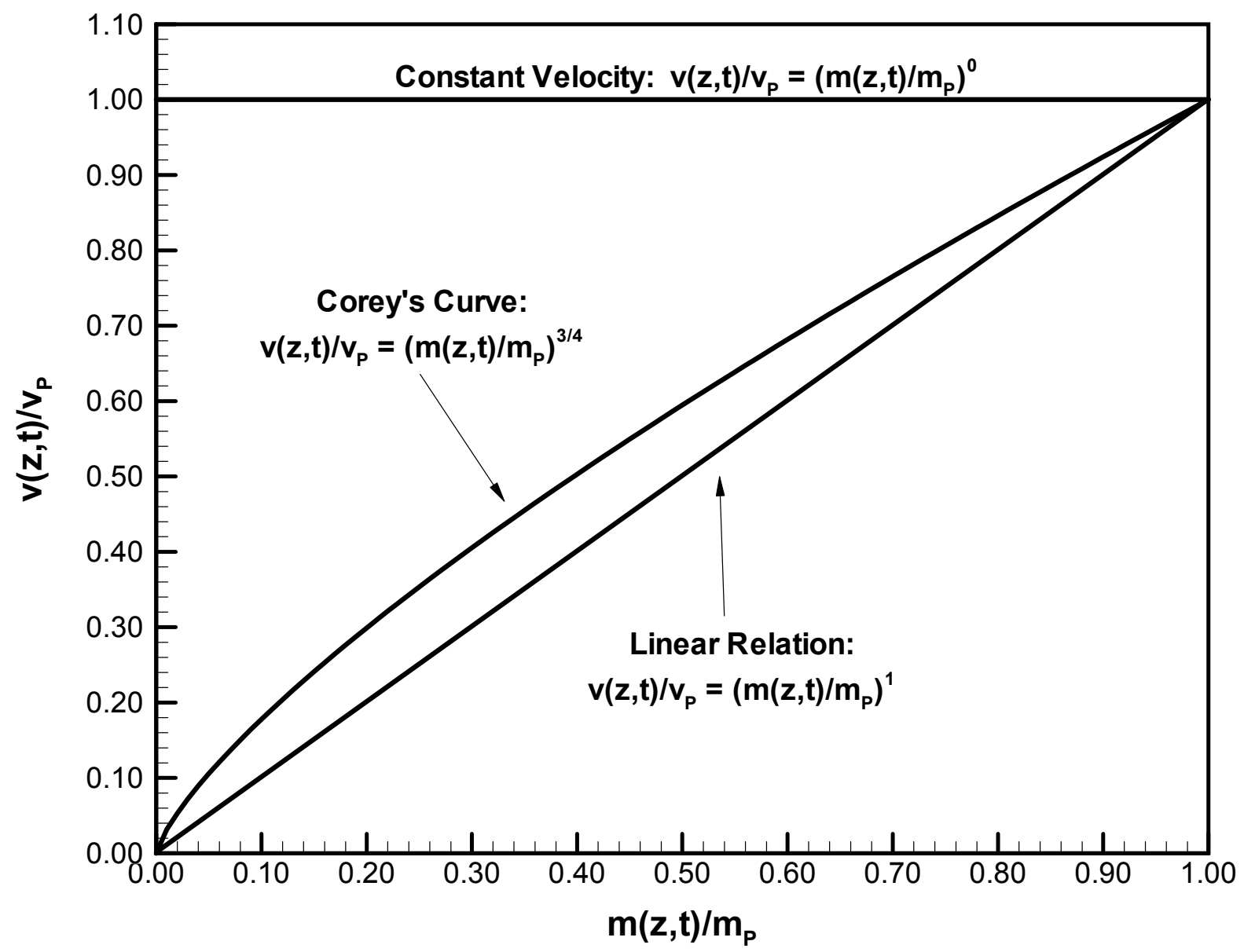

Figure 2: Different concepts for change of flow velocity as a function of mass flow rate 


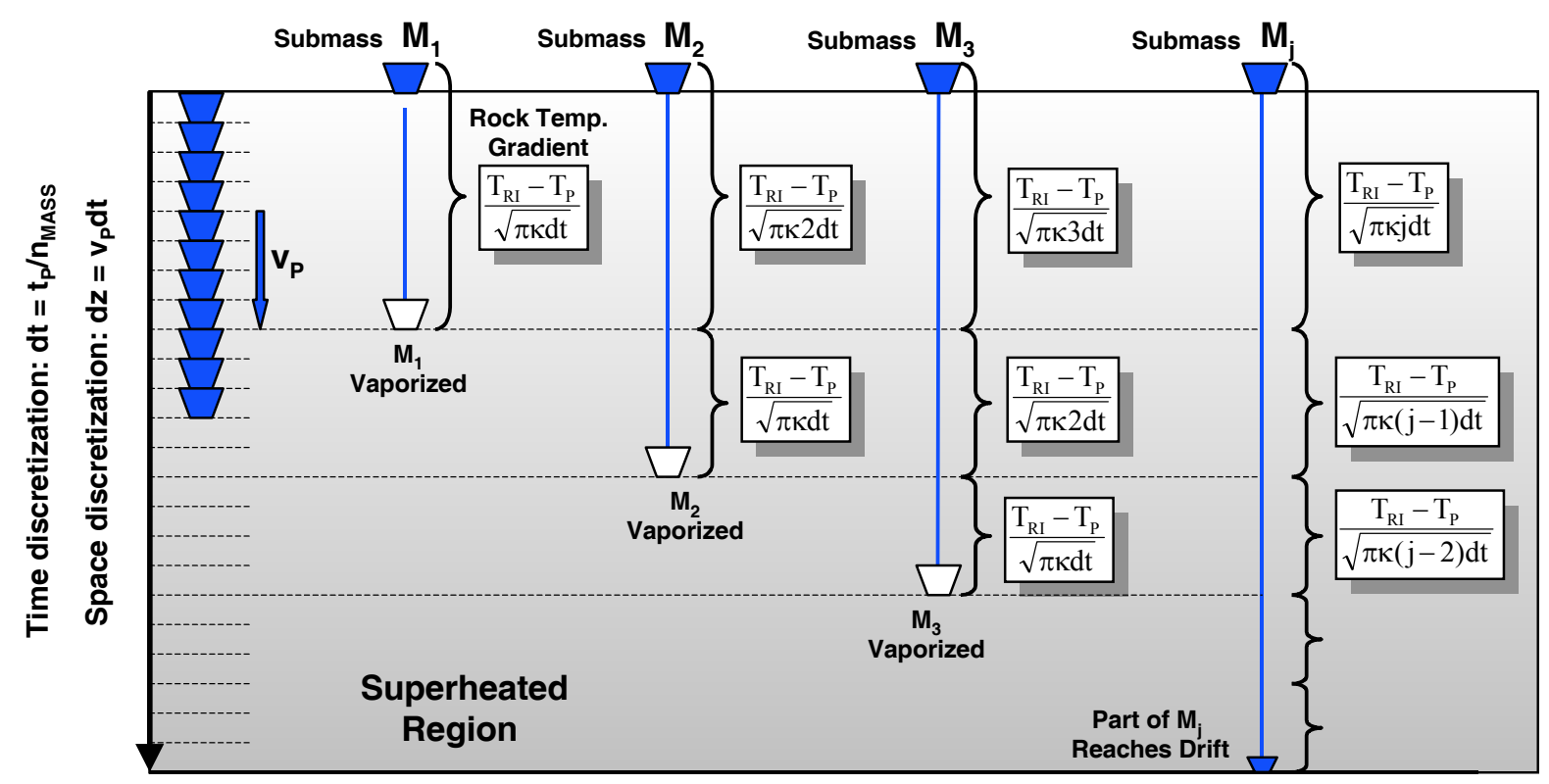

Drift Crown

Figure 3: Schematic illustration of the time-marching algorithm proposed for the flow of finite submasses $\mathrm{M}_{\mathrm{j}}$ introduced into superheated rock 


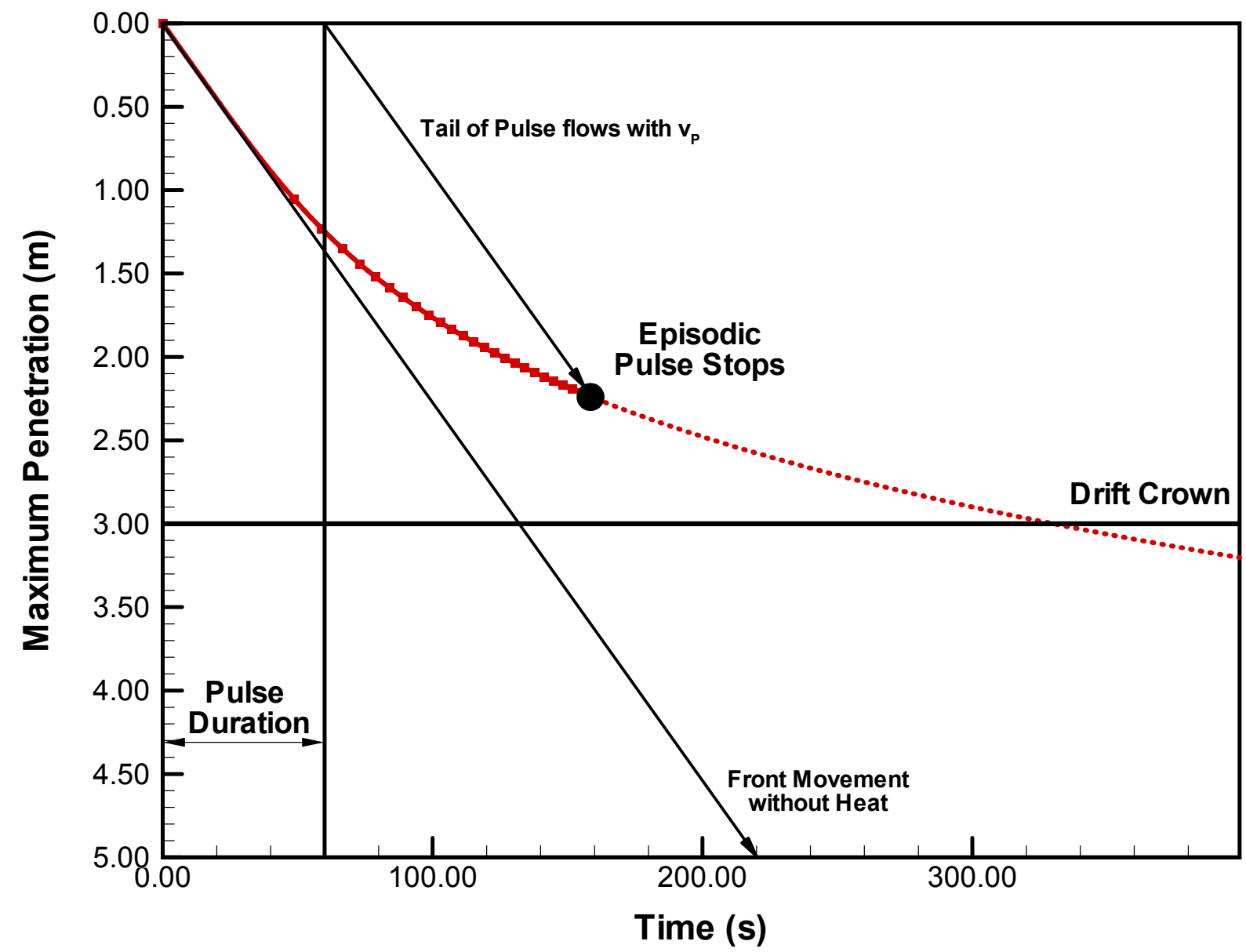

Figure 4: Penetration distance versus time for infiltration event Case 1

(dashed line: for continuous pulse) 


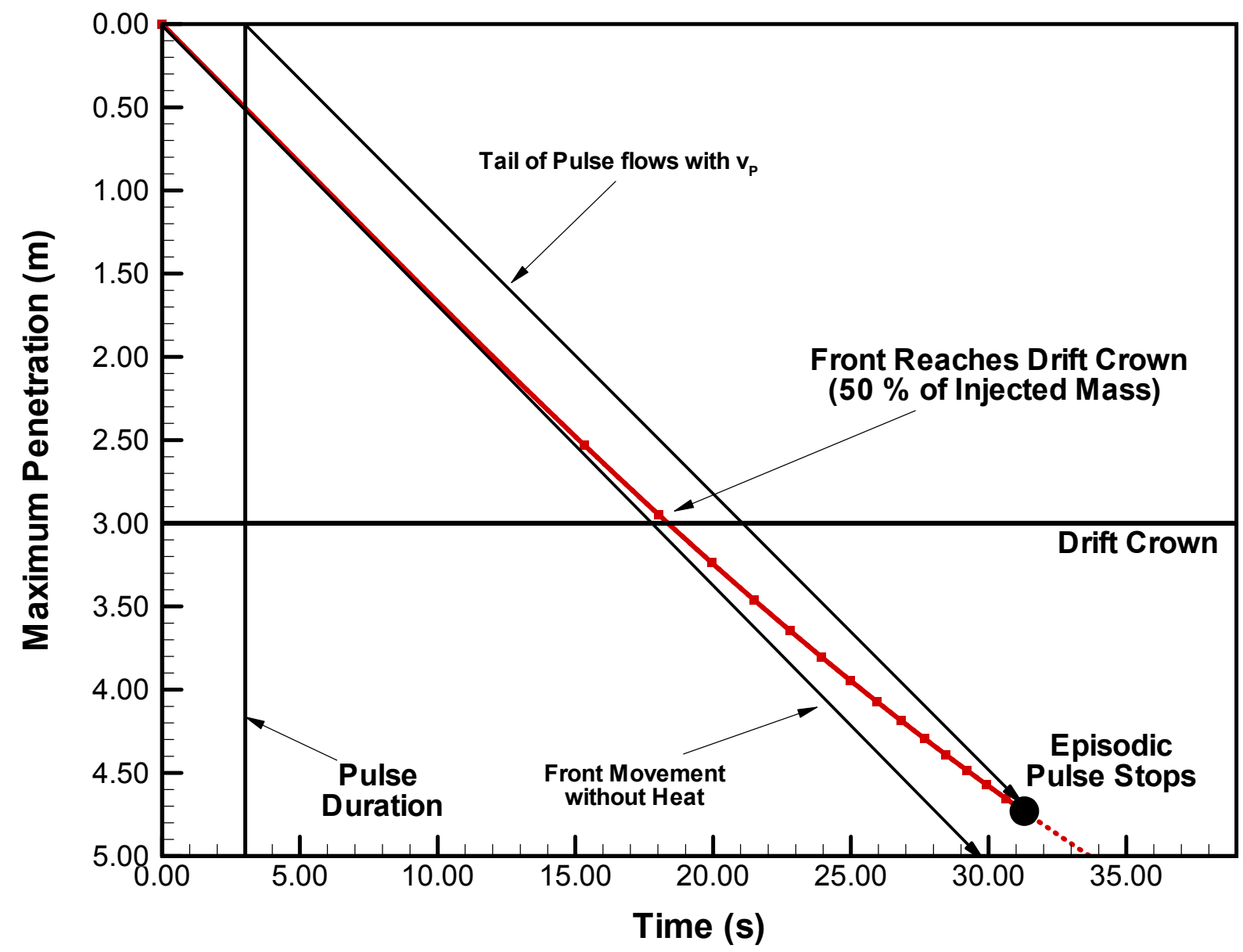

Figure 5: Penetration distance versus time for infiltration event Case 2

(dashed line: for continuous pulse) 


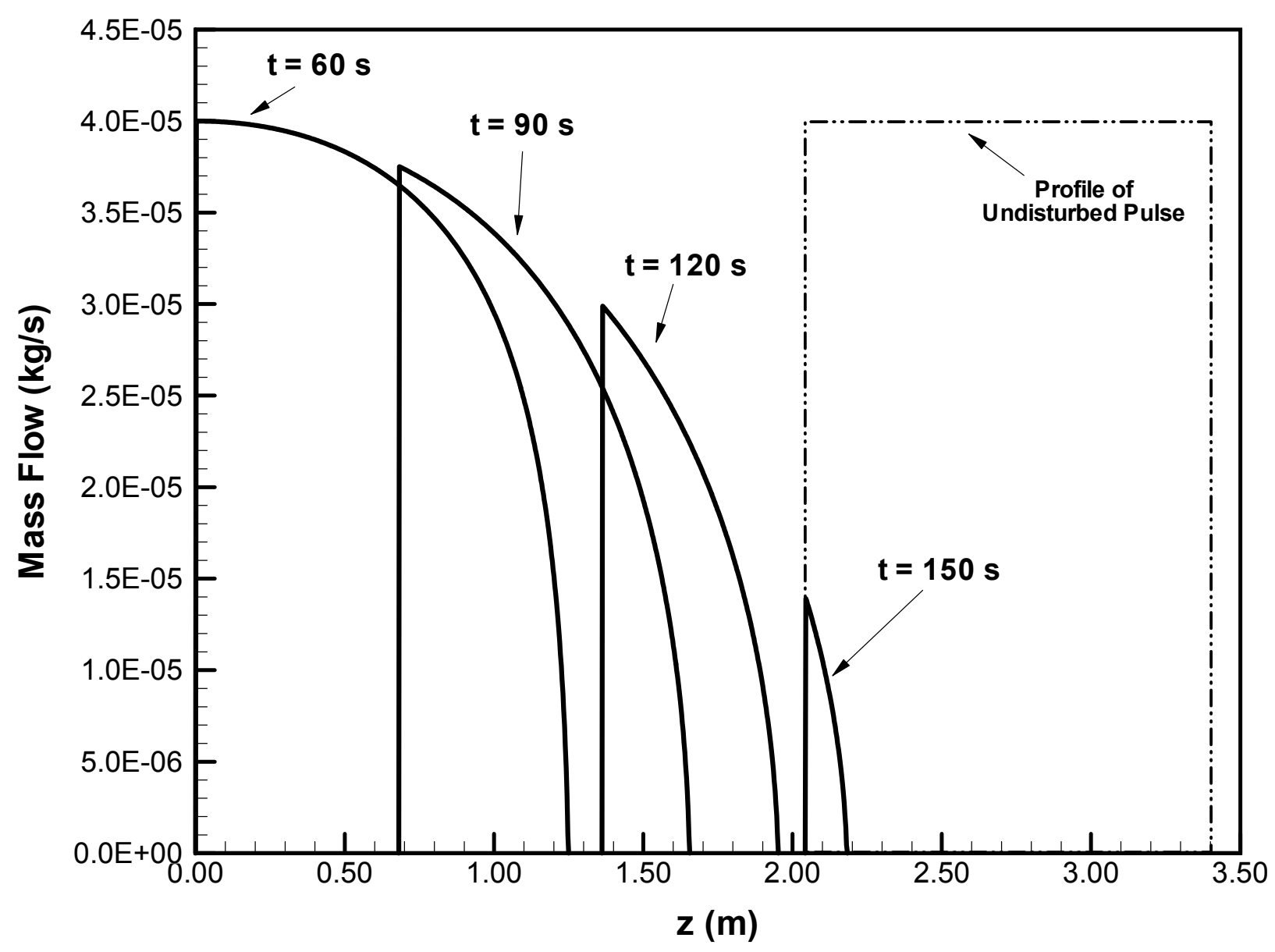

Figure 6: Profiles of mass flow for infiltration event Case 1, at t $=60 \mathrm{~s}, 90 \mathrm{~s}, 120 \mathrm{~s}$, and $150 \mathrm{~s}$ 


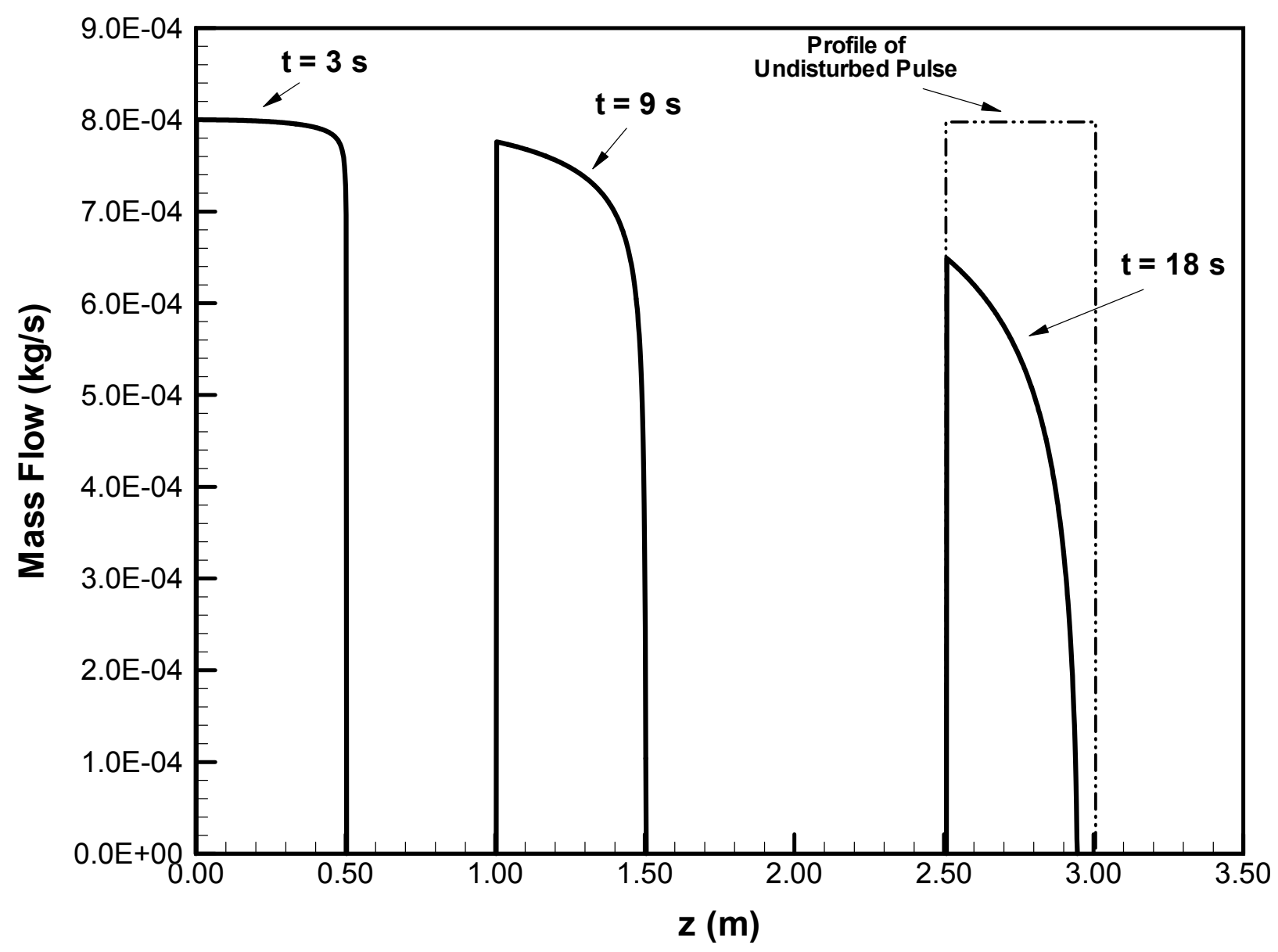

Figure 7: Profiles of mass flow for infiltration event Case 2, at t $=3 \mathrm{~s}, 9 \mathrm{~s}$, and $18 \mathrm{~s}$ 


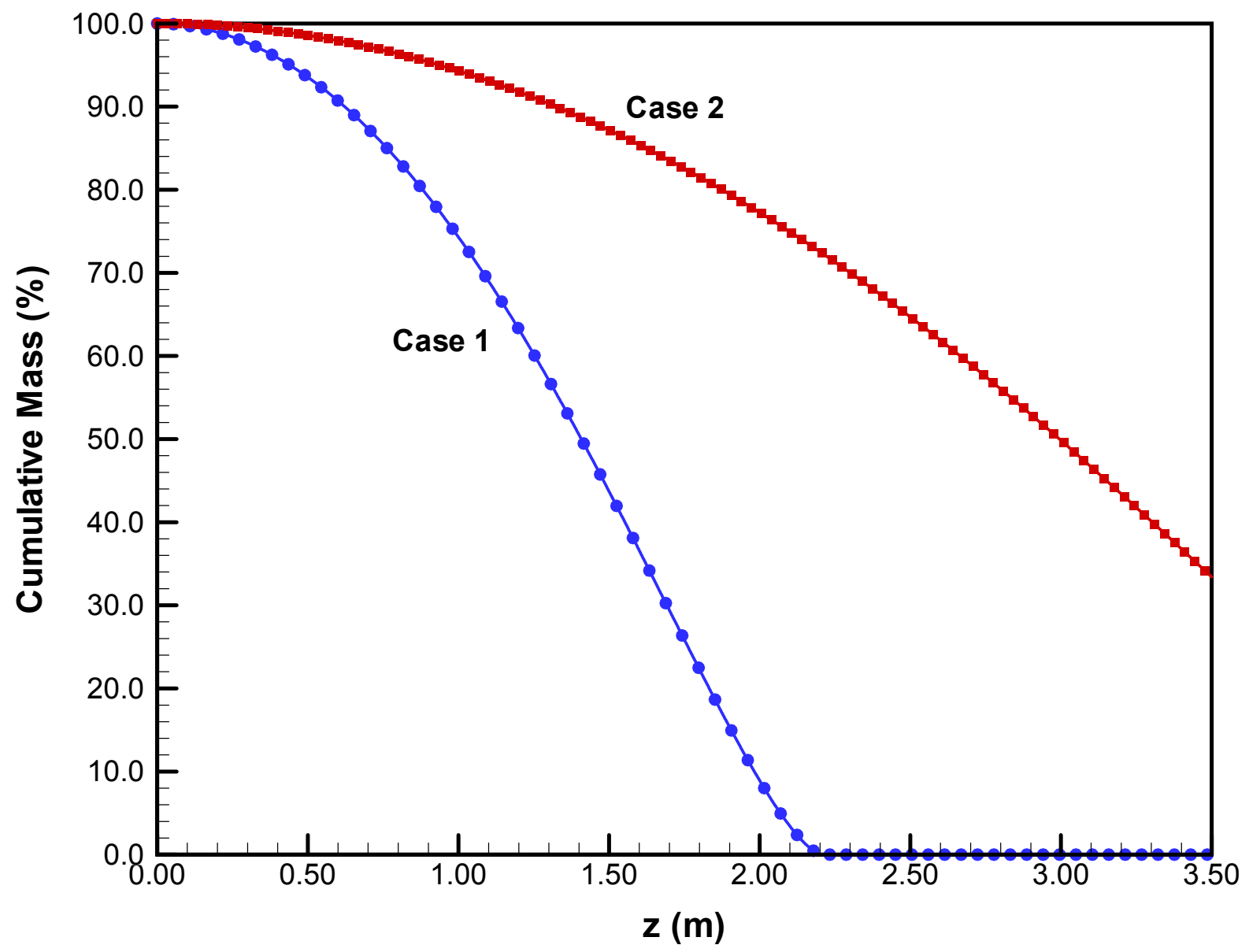

Figure 8: Cumulative mass collected at location z, compared to total injected mass (in \%) 


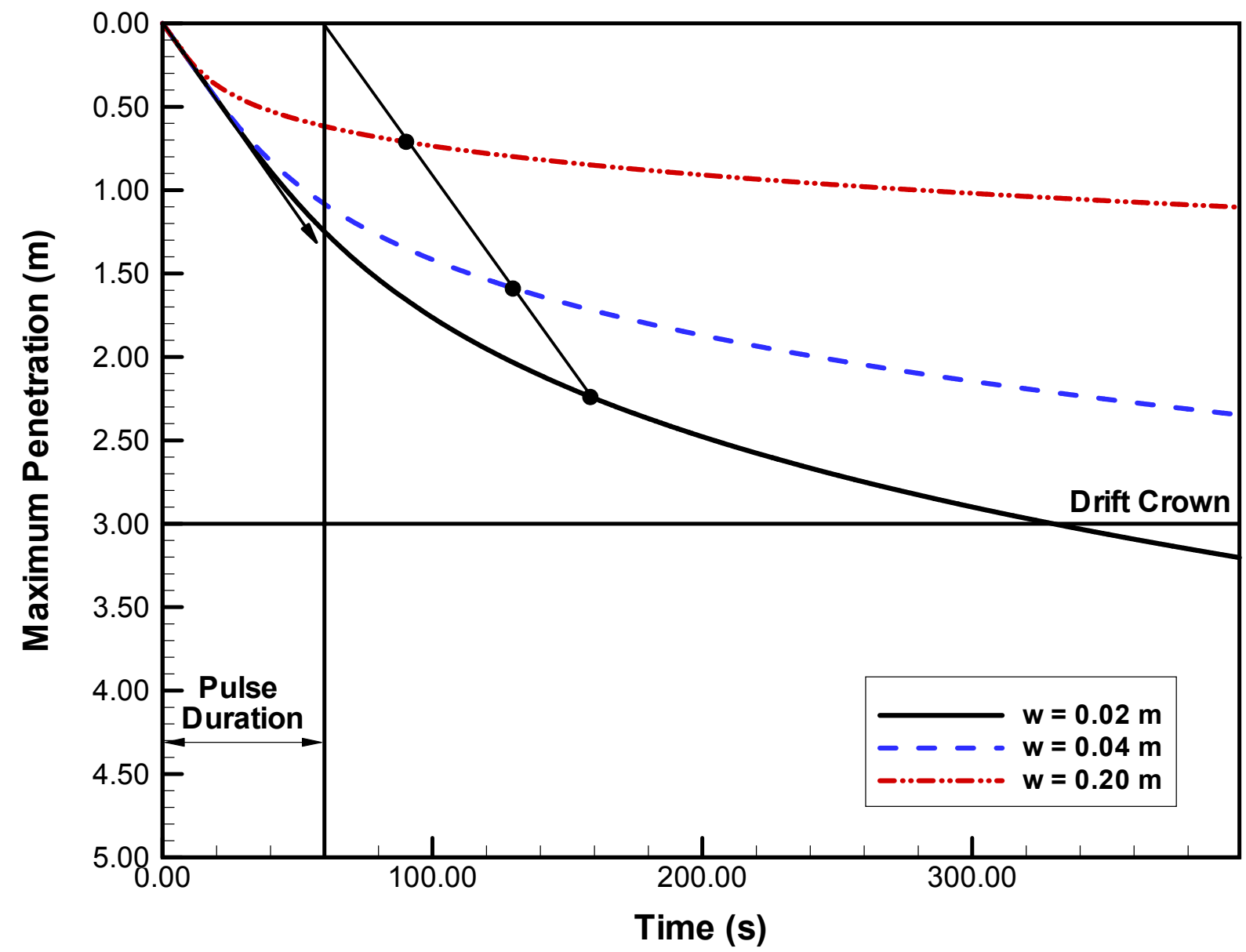

Figure 9: Penetration distance versus time for different ribbon widths. Solid circles indicate location and time where infiltration event $t_{P}=60 \mathrm{~s}$ comes to a final stop. Note that results for $\mathrm{w}=0.04 \mathrm{~m}$ are identical to results for $\mathrm{m}_{\mathrm{P}}=2.0 \times 10^{-5} \mathrm{~kg} / \mathrm{s}$ or $\beta=10^{\circ} \mathrm{C} / \mathrm{m}$. Results for $\mathrm{W}=0.2 \mathrm{~m}$ are identical to results for $\mathrm{m}_{\mathrm{P}}=4.0 \times 10^{-6} \mathrm{~kg} / \mathrm{s}$. 


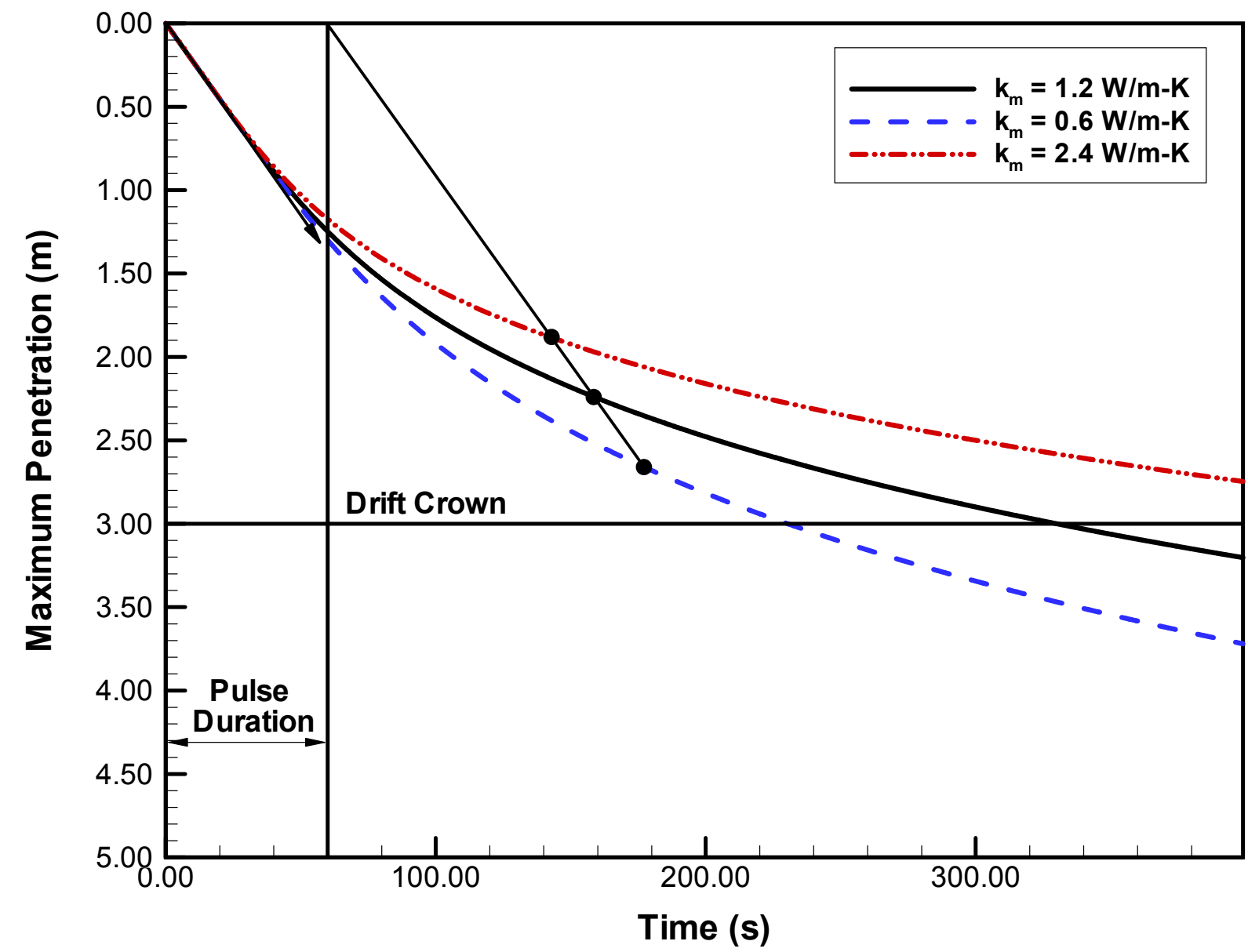

Figure 10: Penetration distance versus time for different thermal conductivities. Solid circles indicate location and time where infiltration event $t_{P}=60 \mathrm{~s}$ comes to a final stop. 


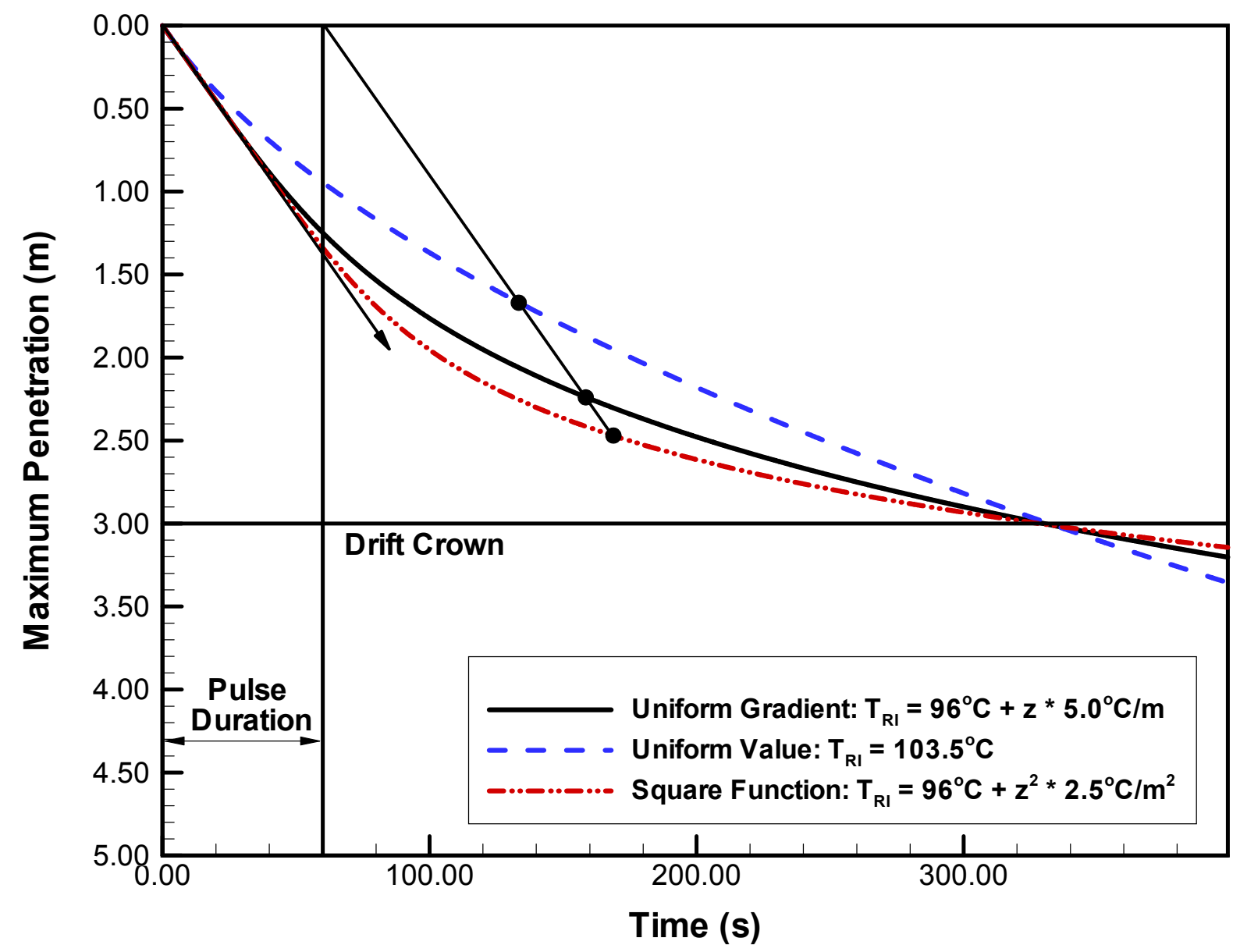

Figure 11: Penetration distance versus time for different initial rock temperature distributions. Solid circles indicate location and time where infiltration event $t_{P}=60 \mathrm{~s}$ comes to a final stop. 


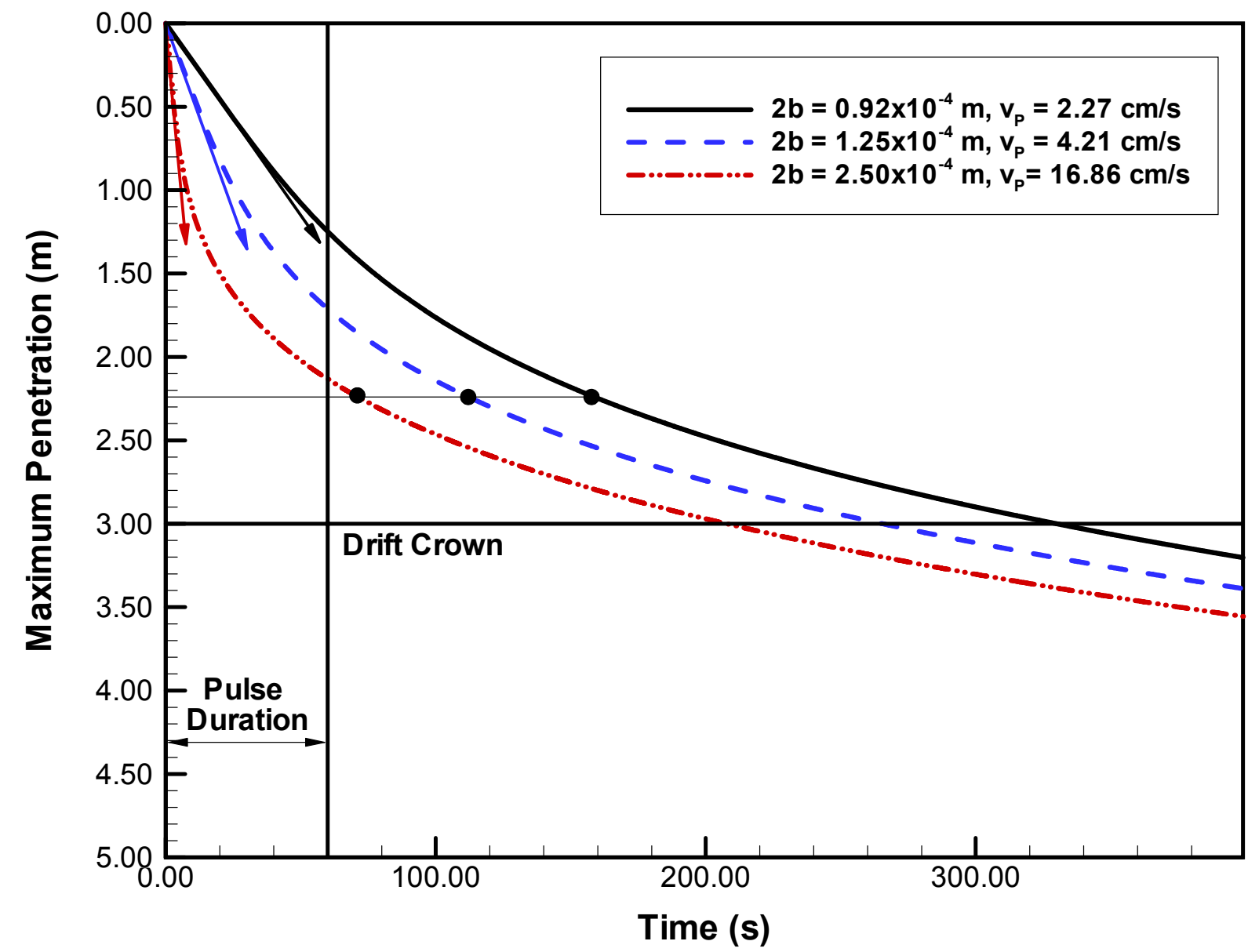

Figure 12: Penetration distance versus time for different fracture apertures. Solid circles indicate location and time where infiltration event $t_{P}=60 \mathrm{~s}$ comes to a final stop. 


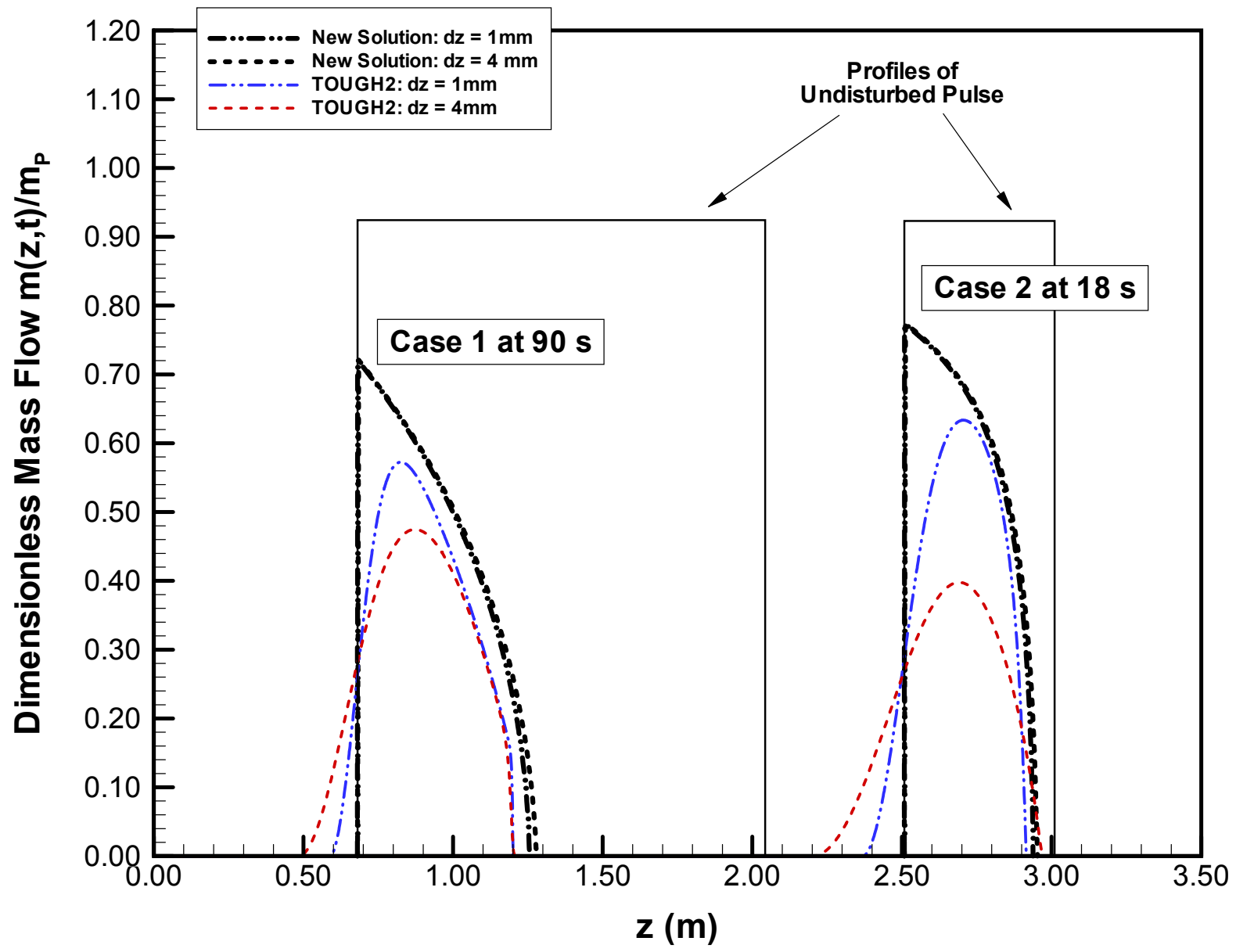

Figure 13: Profiles of dimensionless mass flow for infiltration event Case 1 at $\mathrm{t}=90 \mathrm{~s}$ and infiltration event Case 2 at $18 \mathrm{~s}$. The initial rock temperature is uniform. Results compare new solution scheme with TOUGH2 simulation, using two different vertical discretization lengths of $1 \mathrm{~mm}$ and $4 \mathrm{~mm}$. In Case 1, maximum pulse penetration for the new solution scheme is $1.68 \mathrm{~m}$ with $\mathrm{dz}=1 \mathrm{~mm}$ and $1.64 \mathrm{~m}$ with $\mathrm{dz}=4 \mathrm{~mm}$, while TOUGH2 results give $1.42 \mathrm{~m}$ with $\mathrm{dz}=1 \mathrm{~mm}$ and $1.36 \mathrm{~m}$ with $\mathrm{dz}=4 \mathrm{~mm}$. In Case 2 , the cumulative amount of water collected at $\mathrm{L}=3 \mathrm{~m}$ is $50 \%$ of total injected water for both discretizations using the new solution scheme, compared to $39 \%$ for TOUGH 2 run with $\mathrm{dz}=1 \mathrm{~mm}$ and $30 \%$ for TOUGH 2 run with $4 \mathrm{~mm}$. 


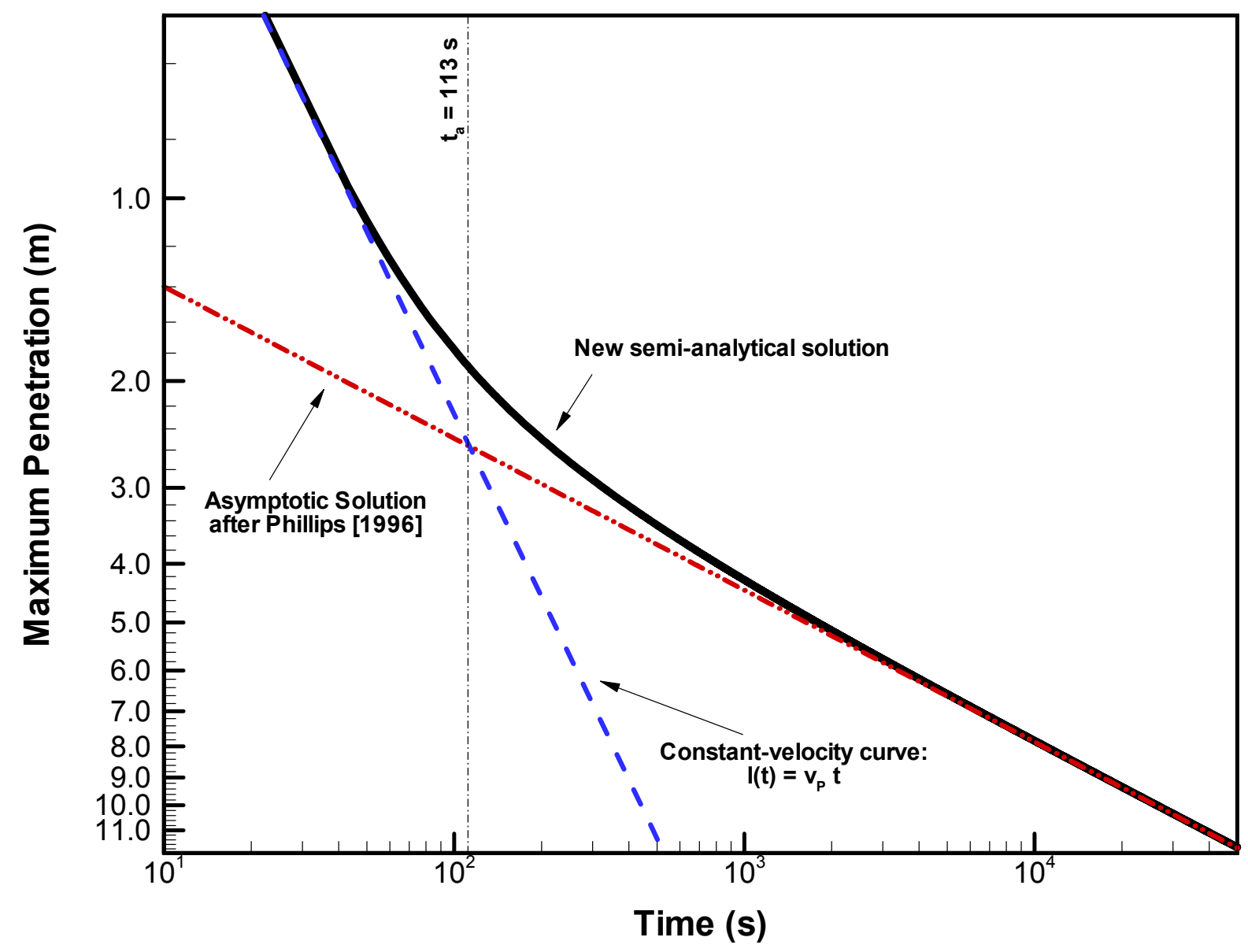

Figure 14: Penetration distance versus time, for continuous infiltration. Results compare new solution scheme with analytical solution for asymptotic long-term behavior. 